\title{
COVID-19: Factors associated with psychological distress, fear, and coping strategies among community members across 17 countries
}

Muhammad Aziz Rahman 1,2,3* D, Sheikh Mohammed Shariful Islam ${ }^{4}$, Patraporn Tungpunkom ${ }^{5}$, Farhana Sultana ${ }^{6}$, Sheikh M. Alif ${ }^{7}$, Biswajit Banik', Masudus Salehin ${ }^{1}$, Bindu Joseph ${ }^{1}$, Louisa Lam ${ }^{1}$, Mimmie Claudine Watts ${ }^{1}$, Sabria Jihan Khan ${ }^{8}$, Sherief Ghozy ${ }^{9}$, Sek Ying Chair ${ }^{10}$, Wai Tong Chien ${ }^{10}$, Carlos Schönfeldt-Lecuona ${ }^{11}$, Nashwa El-Khazragy ${ }^{12}$, llias Mahmud ${ }^{13}$, Adhra Hilal Al Mawali ${ }^{14}$, Turkiya Saleh Al Maskari ${ }^{15}$, Rayan Jafnan Alharbi ${ }^{16}$, Amr Hamza ${ }^{17}$, Mohamad Ali Keblawi ${ }^{17}$, Majeda Hammoud ${ }^{18}$, Asmaa M. Elaidy ${ }^{19}$, Agus Dwi Susanto ${ }^{20}$, Ahmed Suparno Bahar Moni ${ }^{21}$, Alaa Ashraf AlQurashi ${ }^{22}$, Almajdoub Ali ${ }^{23}$, Amit Wazib $^{24}$,

Cattaliya Siripattarakul Sanluang ${ }^{5}$, Deena H. Elsori ${ }^{25}$, Farhana Yasmin ${ }^{26}$, Feni Fitrani Taufik ${ }^{20}$, Manal Al Kloub ${ }^{27}$, Mara Gerbabe Ruiz ${ }^{15}$, Mohamed Elsayed ${ }^{28}$, Nael Kamel Eltewacy ${ }^{29}$, Nahed Al Laham ${ }^{30}$, Natalia Oli ${ }^{31}$, Ramy Abdelnaby ${ }^{32}$, Rania Dweik ${ }^{25}$, Ratree Thongyu ${ }^{33}$, Sami Almustanyir ${ }^{34}$, Shaila Rahman ${ }^{24}$, Sirirat Nitayawann, Sondos Al-Madhoun ${ }^{30}$, Suwit Inthong ${ }^{5}$, Talal Ali Alharbi ${ }^{35}$, Tamanna Bahar ${ }^{36}$, Tribowo Tuahta Ginting ${ }^{37}$ and Wendy M. Cross ${ }^{1}$

\section{Abstract}

Background: The current pandemic of COVID-19 impacted the psychological wellbeing of populations globally. Objectives: We aimed to examine the extent and identify factors associated with psychological distress, fear of COVID-19 and coping.

Methods: We conducted a cross-sectional study across 17 countries during Jun-2020 to Jan-2021. Levels of psychological distress (Kessler Psychological Distress Scale), fear of COVID-19 (Fear of COVID-19 Scale), and coping (Brief Resilient Coping Scale) were assessed.

\footnotetext{
*Correspondence: ma.rahman@federation.edu.au; aziz.rahman@y7mail.com

${ }^{1}$ School of Health, Federation University Australia, Berwick, Victoria, Australia ${ }^{2}$ Australia Institute for Primary Care and Ageing (AIPCA), La Trobe University, Melbourne, Victoria, Australia

Full list of author information is available at the end of the article
}

C C The Author(s). 2021 Open Access This article is licensed under a Creative Commons Attribution 4.0 International License, which permits use, sharing, adaptation, distribution and reproduction in any medium or format, as long as you give appropriate credit to the original author(s) and the source, provide a link to the Creative Commons licence, and indicate if changes were made. The images or other third party material in this article are included in the article's Creative Commons licence, unless indicated otherwise in a credit line to the material. If material is not included in the article's Creative Commons licence and your intended use is not permitted by statutory regulation or exceeds the permitted use, you will need to obtain permission directly from the copyright holder. To view a copy of this licence, visit http://creativecommons.org/licenses/by/4.0/. The Creative Commons Public Domain Dedication waiver (http://creativecommons.org/publicdomain/zero/1.0/) applies to the data made available in this article, unless otherwise stated in a credit line to the data. 
Results: A total of 8,559 people participated; mean age $( \pm$ SD) was $33( \pm 13)$ years, $64 \%$ were females and $40 \%$ selfidentified as frontline workers. More than two-thirds (69\%) experienced moderate-to-very high levels of psychological distress, which was $46 \%$ in Thailand and $91 \%$ in Egypt. A quarter (24\%) had high levels of fear of COVID-19, which was as low as 9\% in Libya and as high as 38\% in Bangladesh. More than half (57\%) exhibited medium to high resilient coping; the lowest prevalence (3\%) was reported in Australia and the highest (72\%) in Syria. Being female (AOR 1.31 [95\% Cls 1.09-1.57]), perceived distress due to change of employment status (1.56 [1.29-1.90]), comorbidity with mental health conditions (3.02 [1.20-7.60]) were associated with higher levels of psychological distress and fear. Doctors had higher psychological distress (1.43 [1.04-1.97]), but low levels of fear of COVID-19 (0.55 [0.41-0.76]); nurses had medium to high resilient coping (1.30 [1.03-1.65]).

Conclusions: The extent of psychological distress, fear of COVID-19 and coping varied by country; however, we identified few higher risk groups who were more vulnerable than others. There is an urgent need to prioritise health and well-being of those people through well-designed intervention that may need to be tailored to meet country specific requirements.

Keywords: COVID-19, coronavirus, mental health, psychological distress, fear, coping, resilience

\section{Introduction}

The COVID-19 pandemic, with more than 226 million cases and 4.7 million deaths by mid Sep-2021, has occurred in waves [1]. The first wave raised the alarm of what was imminent; the second wave identified the incountry differences in incidence, prevalence and mortality rates as well as health system gaps, notwithstanding policy failures; while the third wave further exposed varying social, financial, policy and failures in the health system management on the global scale.

COVID-19 impacted psychological wellbeing of global populations. Studies revealed that COVID-19 pandemic affected people in discrete ways across the world and exposed varying degrees of vulnerability among divergent community members. Evidence linked emotional stress to disasters, quarantine and lockdown, where people in uncertain situations used to lose the power to predict and control their lives under conditions of threat [2]. Prevalence of psychological distress, anxiety and depression during the COVID-19 pandemic was reported as 50\%, $27 \%$ and $28 \%$ respectively, in a systematic review with 398,771 participants [3]. Psychological distress had been shown to be more prevalent among middle-aged single women and mothers, and those in lower-income groups [4]. A recent review of the psychological effects of COVID-19 related lockdown reported many negative psychological effects associated with quarantine including fear, stress, insomnia, depression, frustration, and anger and some of those persisted post quarantine period [5].

Factors associated with psychological wellbeing during the current COVID-19 pandemic were diverse. However, the primary reasons for COVID-related stress were associated with contracting the virus, related complications, restrictions and mandated lockdowns, social isolation, financial loss, lack of income and disruption of daily routines which have been observed globally [6]. Moreover, critical incidents such as deaths of family members, preexisting stressors, being older and migrant were substantial grounds for poor mental health outcomes [7]. An international study of 18 countries examining the mental health outcomes related to mandatory lockdowns showed that half of the study population $(n=9,565)$ expressed moderate mental wellbeing; financial impacts along with lack of access to basic needs were identified as substantial grounds for such poor mental health outcomes [8]. A recent Australian study also found that people with higher psychological distress increased smoking and alcohol consumption during the pandemic period; females and people with pre-existing mental health conditions were more likely to experience higher levels of psychological distress [9]. Furthermore, being on the frontline, health care workers also confronted physical and mental health consequences of COVID 19 crisis [10].

COVID-19 was unpredictable. Varying degrees of lockdown or isolation measures were implemented nationally, depending on the stage of the pandemic. Most of the published studies examined psychological impacts of COVID-19 in a single country or small communities. A recent systematic review and meta-analysis showed that Black and Asian ethnic community people were at increased risk of COVID-19 infection, intensive care admission and deaths [11]. Evidence from multicultural communities on a global scale was lacking. Unless the issues of COVID-related mental wellbeing were addressed in a timely manner, such impacts could potentially translate into a range of long-term illnesses with severe economic impacts. As COVID-19 continued to peak in many countries, it was imperative that ongoing planning with mental health support strategies and early identification of psychological distress were realised, because people had the ability to normalise stressful situations 
when they had access to support networks and resources [12]. Therefore, our study aimed to examine the extent of and the factors associated with psychological distress, the level of fear of COVID-19 and coping strategies amongst a diverse range of community people in multicountry settings.

\section{Materials and methods}

\section{Study design and settings}

We conducted a cross-sectional study across 17 countries utilizing web-based online platforms. Participating countries included Australia, Bangladesh, Egypt, China (Hong Kong), Indonesia, Jordan, Kuwait, Libya, Malaysia, Nepal, Oman, Pakistan, Palestine, Saudi Arabia, Syria, Thailand, and the United Arab Emirates (UAE). Those countries were selected based on the existing collaborative relationships with the first author.

\section{Study population}

Adults aged $\geq 18$ years, living in the participating countries, able to respond to an online questionnaire in English/ Arabic/ Thai/ Nepali were eligible. Thus, study participants included general community members, healthcare professionals, patients, university students and staff. Patients were defined as individuals who attended a general practice or an allied healthcare setting (for any medical condition including COVID-19 related illness) in the previous four weeks at the time of data collection. Frontline or essential service workers were defined as individuals who selfidentified themselves as being in contact with patients/clients during the pandemic period.

\section{Sampling}

Sample size was calculated using OpenEpi. Study population and estimated prevalence of stress varied across the participating countries. Therefore, keeping the population size as $100,000,000$, assuming $50 \%$ prevalence of stress globally, $95 \%$ confidence intervals and $80 \%$ power, the estimated minimum sample size was 385 . That number was the highest possible number, even if the population size and the prevalence of stress varied across countries. Therefore, careful consideration and taking into account the opinion of the cooperating countries, we agreed a minimum sample size of 385 participants for each collaborating country.

\section{Data collection}

An online link was created with a structured survey questionnaire using the Google form. Data were collected in Jun-2020 in Australia, Aug-Sep-2020 in Bangladesh and Malaysia, and during Nov-2020 to Jan-2021 for the other 14 countries. A separate link was created for each language (English, Arabic, Thai and Nepali). The plain language information statement (PLIS) and the consent form appeared on the first screen. Only participants, who provided consent and met the eligibility criteria, could move to the next screen. The subsequent seven screens contained the full study questionnaire, comprising of 39 questions. All responses were anonymous.

The English version of the PLIS, consent form and the study questionnaire were translated into other languages as mentioned above, back-translated to English, reviewed and pilot-tested by the team of local lead investigators for Arabic (Egypt, Saudi Arabia, UAE), Thai (Thailand) and Nepali (Nepal) versions. An invitation with the online survey link and QR code were shared using different social media platforms, online community networks, staff and student email databases of participating universities/hospitals. Text messages using SMS, Viber, WhatsApp were also shared. Flyers containing the QR codes of the study were also distributed and posted in university/healthcare settings. The survey was open to minimise selection bias, so anyone having the survey link could participate in the study; and no incentives were provided for participation in the study.

\section{Study tool}

The structured survey questionnaire was adapted from the previous study conducted in Australia [9]. The survey questionnaire was pre-tested across different electronic devices. Psychological distress was measured using the Kessler Psychological Distress Scale (K-10) having 10-items, [13] fear was measured using the Fear of COVID-19 Scale (FCV-19S) having 7-items, [14] and coping was measured using Brief Resilient Coping Scale (BRCS) having 4-items [15]. Reliability of those tools in the English version was examined in the Australian study, and it was found that they worked for migrants and non-migrants [16].

\section{Data analyses}

The database was downloaded from the Google platform and Stata statistical software Stata/SE V.15.0 for Windows (StataCorp, College Station, USA, 2017) was used for data analyses. Descriptive statistics, including frequencies and percentages, were generated for categorical variables; means and standard deviations (SD) were generated for continuous variables. Psychological distress (based on the K-10 scoring) was categorised into low (score 10-15) and moderate to very high (score 16-50), fear of COVID-19 (based on the FCV195 scoring) was categorised into low (score 7-21) and high (score 22-35), and coping (based on the BRCS scoring) was categorised into low (score 4-13) and medium to high (score 14-20).

Univariate and multivariate logistic regression analyses were conducted to examine the association between 
variables. Multivariate analyses were conducted to control potential confounders and the results are presented with odds ratios (ORs), adjusted ORs (AOR) and 95\% confidence intervals (CIs). We also tested the sensitivity of analyses by excluding the non-significant association from the univariate model, but no changes were observed in the adjusted model. We investigated potential effect modification between age groups, gender and psychological distress, fear of COVID-19 and coping strategies. The additive log risk model was compared with multiplicative odds ratio model using the likelihood ratio test and Bayesian information criterion. A cut-off of $\mathrm{p}<$ 0.05 was considered as statistically significant. For the country-wise comparison, we selected the reference country based on the lowest prevalence of moderate to very high psychological distress, lowest prevalence of high level of fear of COVID-19 and lowest prevalence of medium to high resilience coping, then we organised other countries chronologically for each outcome based on the scores prior to conducting the multivariate analyses.

\section{Ethics}

Ethics approval was obtained from the Human Research Ethics Committee from each participating country. The survey was voluntary in nature and participants got the opportunity to have informed decision to participate in the study. Privacy and confidentiality of the collected data were maintained.

\section{Results}

A total of 8987 individuals from 17 countries met the eligibility criteria and consented to participate in the study. However, 8559 of them (95\%) completed the questionnaire and were included for analyses. Most countries contributed $6-7 \%$ of the study population except Bangladesh (11\%) and Saudi Arabia (9\%). Mean age $( \pm \mathrm{SD})$ of the participants was $33( \pm 13)$ years and twothirds (64\%) were females. More than one-third (42\%) had a source of income during the pandemic, while 51\% had their jobs adversely affected by COVID-19. More than one-third (40\%) self-identified as frontline or essential service workers, which included $14 \%$ doctors and $16 \%$ nurses. Only $4 \%$ reported having a history of psychiatric or mental health issues. The majority $(81 \%)$ had never been smokers, and only $11 \%$ reported drinking alcohol in the last four weeks prior to data collection. One in five participants $(\mathrm{n}=1780 ; 21 \%)$ had direct contact and 952 (11\%) participants had indirect contact with known/ suspected COVID-19 cases. About 6\% tested positive for COVID-19, and $14 \%$ reported self-isolating before receiving negative test results. A third of the study participants $(\mathrm{n}=2752 ; 33 \%)$ visited a healthcare provider (and were defined as 'patients' in this study) and one in ten study participants $(\mathrm{n}=1081 ; 13 \%)$ used healthcare service due to COVID-19 related stress in the last six months. Table 1 shows the characteristics of the study population.

More than two-thirds of the study participants $(\mathrm{n}=$ 5846; 69\%) experienced moderate to very high levels of psychological distress, a quarter $(\mathrm{n}=2066 ; 24 \%)$ had high levels of fear of COVID-19, and 4815 (57\%) exhibited medium to high resilient coping (Tables S.1, S.2, S.3).

\section{Psychological distress}

The univariate analyses showed reasonable evidence against the null hypothesis of no association between moderate to very high levels of psychological distress and a number of variables (Table 2). However, when adjusted for potential confounders, being female, perceived distress due to change of employment status, self-identification as a doctor, being affected by the change of financial situation, comorbidity with mental health conditions, unsure and indirect contact with COVID-19 patient, being a patient, use of healthcare service to overcome COVID-related stress, and higher levels of fear of COVID-19 were found to be associated with moderate to very high levels of psychological distress. We did not identify any effect modification between age groups, gender, and psychological distress.

\section{Levels of fear}

Similar to psychological distress, participants from all 17 countries demonstrated significant levels of fear to COVID 19 (Table 3). After adjusting for potential confounders, high levels of fear were associated with being aged 30-59 years, being female, perceived distress due to a change of employment status, self-identification as a frontline or essential service worker, being affected by the change of financial situation, having comorbidities, drinking alcohol in the previous four weeks, unsure contact with a COVID-19 case, health service use to overcome COVID-related stress, and having moderate to very high levels of psychological distress. We did observe some effect modification with gender and fear of COVID-19 (contact with a COVID-19 patient) (data not shown).

\section{Coping strategies}

Table 4 shows the univariate analyses identifying significant association between medium to high resilient coping and other variables. From the multivariate analyses, we identified that participants who were $\geq 60$ years old, self-identification as a nurse, whose financial situation was impacted negatively, who perceived their own mental health as good to excellent, who 
Table 1 Characteristics of the study population

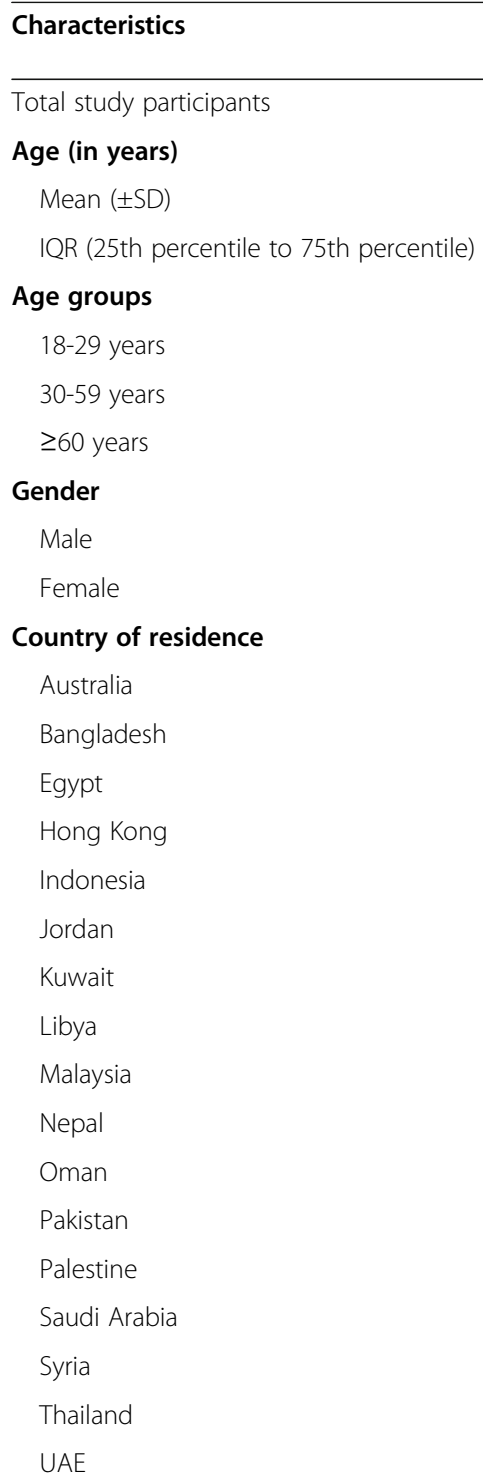

Born in the same country of residence

No

Yes

\section{Living status}

Live without family members

Live with family members

Highest educational/vocational qualification

$$
\begin{aligned}
& \text { Primary/Grade } 1 \text { to } 6 \\
& \text { Secondary/Higher Secondary/Grade } 7 \text { to } 12 \\
& \text { Certificate/Diploma/Trade qualifications } \\
& \text { Bachelor/Masters/PhD }
\end{aligned}
$$

\section{Current employment condition}

Unemployed/Housewife/Home maker/Home duties (No source of income)

Jobs affected by COVID-19 (lost job/working hours
Total, n(\%)

8559

7665

$33.3(12.5)$

23-41

7664

$3683(48.1)$

3646 (47.6)

$335(4.4)$

8475

3016 (35.6)

5459 (64.4)

8559

587 (6.9)

$962(11.2)$

416 (4.9)

555 (6.5)

$541(6.3)$

538 (6.3)

417 (4.9)

114 (1.3)

720 (8.4)

311 (3.6)

437 (5.1)

418 (4.9)

417 (4.9)

803 (9.4)

408 (4.8)

498 (5.8)

417 (4.9)

8463

1310 (15.3)

7153 (83.6)

8441

1908 (22.6)

6533 (77.4)

8449

$62(0.7)$

1546 (18.3)

877 (10.4)

5964 (70.6)

8206

$643(7.8)$

4148 (50.5)
Table 1 Characteristics of the study population (Continued)

\begin{tabular}{ll}
\hline Characteristics & $\begin{array}{l}\text { Total, } \\
\mathbf{n}(\%)\end{array}$ \\
\hline $\begin{array}{l}\text { reduced/afraid of job loss) } \\
\text { Have an income source (employed/Government } \\
\text { benefits) }\end{array}$ & $3415(41.6)$ \\
$\begin{array}{l}\text { Perceived distress due to change of employment } \\
\text { status }\end{array}$ & $\mathbf{7 2 6 8}$ \\
$\quad \begin{array}{l}\text { A little to none } \\
\quad \text { Moderate to a great deal }\end{array}$ & $4712(61.8)$ \\
$\begin{array}{l}\text { Improved working situation due to change of } \\
\text { employment situation }\end{array}$ & $2916(38.2)$ \\
$\quad \begin{array}{l}\text { A little to none } \\
\text { Moderate to a great deal }\end{array}$ & $4473(76.8)$ \\
Self-identification as a frontline or essential service & $\mathbf{8 4 7 6}$
\end{tabular}
worker

$5046(59.5)$

$3430(40.1)$

Yes

Self-identification as a healthcare worker

6290

No

$3843(61.1)$

Yes, doctor

$887(14.1)$

Yes, nurse

Yes, other healthcare worker

$1032(16.4)$

$528(8.4)$

COVID-19 impacted financial situation $\quad 8507$

No impact

$3783(44.5)$

Yes, impacted positively

$1017(12.0)$

Yes, impacted negatively

3707 (43.6)

Affected by the change in financial situation

6122

Not at all

$1397(22.8)$

Unsure at this time

$912(14.9)$

Somewhat

$2770(45.2)$

A great extent

$1043(17.0)$

Co-morbidities

8416

No

Mental health issue

5975 (71.0)

$362(4.3)$

Other co-morbidity

$2079(24.7)$

Co-morbidities

8416

No

$5975(71.0)$

Single co-morbidity

1547 (19.3)

Multiple co-morbidities

$474(5.9)$

Smoking

8507

Never smoker

$6910(81.2)$

Ever smoker (Daily/Non-daily/Ex)

1597 (18.8)

Increased smoking over the last 6 months

1018

No

$535(52.6)$

$483(47.4)$

Current alcohol drinking (last 4 weeks)

8365

$7435(88.9)$ 
Table 1 Characteristics of the study population (Continued)

Characteristics
Yes
Increased alcohol drinking over the last 6 months
No
Yes
Contact with known/suspected case of COVID-19
No
Unsure
Yes, indirect contact
Yes, provided direct care

Experience related to COVID-19 pandemic (multiple responses possible)

No known exposure to COVID-19
Tested positive for COVID-19
Tested negative for COVID-19 by self-isolated
Had recent overseas travel history and was in
quarantine

Self-identification as a patient (visited a healthcare provider in the last 6 months)

No
Yes
Healthcare service use in the last 6 months
In-person visit to a healthcare provider
Telehealth consultation/Use of national helpline
Used both services

Perceived mental health status

Poor to fair

Good to excellent

Healthcare service use to overcome COVID-19 related stress in the last 6 months

No

Yes

Type of healthcare service used to overcome COVID-19 related stress in the last 6 months

\begin{tabular}{ll} 
Consulted a GP & $356(34.2)$ \\
Consulted a Psychologist & $53(5.1)$ \\
Consulted a Psychiatrist & $63(6.1)$ \\
Used specialised mental healthcare settings & $26(2.5)$ \\
Used mental health resources & $93(8.9)$ \\
Used mental health resources available through media & $171(16.4)$ \\
Used mental health support services & $79(7.6)$ \\
Used combination of services & $199(19.1)$ \\
\hline
\end{tabular}
$4899(58.7)$

$710(8.5)$

$952(11.4)$

$1780(21.3)$

8171

6337 (77.6)

494 (6.0)

1135 (13.9)

205 (2.5)

8322

5570 (66.9)

2752 (33.1)

2727

1896 (69.5)

$636(23.3)$

195 (7.2)

6290

1753 (27.9)

$4537(72.1)$

8264

7183 (86.9)

1081 (13.1)

1041 had indirect contact and direct contact with known or suspected cases of COVID-19, and who visited a healthcare provider in the previous six months were more likely to have medium to high resilient coping. We did not identify any effect modification between age group, gender, and coping strategies (data not shown).

\section{Country-wise findings}

Country-wise analyses (Table 5) showed that moderate to very high levels of psychological distress was common in all 17 countries. The lowest prevalence (46\%) was reported from Thailand and the highest (91\%) from Egypt. When other countries were compared considering Thailand as the baseline, it was found that participants from 10 countries (Hong Kong, Oman, Libya, Kuwait, Saudi Arabia, UAE, Jordan, Syria, Palestine and Egypt), demonstrated statistically significant high psychological distress. Prevalence on high levels of fear of COVID-19 varied across 17 countries (Libya: 9\%, Bangladesh: 38\%). Participants from four countries (Oman, Indonesia, Hong Kong and Pakistan) exhibited higher levels of fear of COVID-19 compared to the participants from Libya. Finally, participants from 12 countries (Jordan, Egypt, Saudi Arabia, Kuwait, Hong Kong, UAE, Palestine, Thailand, Oman, Nepal, Indonesia and Syria) demonstrated statistically significant medium to high resilience coping compared to those from Australia.

\section{Discussion}

To our knowledge, this study is one of the few largescale global cross-sectional studies that assessed psychological distress, levels of fear, and coping strategies and their associated factors among community members, frontline workers, and patients across 17 countries during the first and second wave of the COVID19 pandemic. We found that more than two-thirds (69\%) participants experienced moderate to very high levels of psychological distress and about a quarter (24\%) had a high level of fear of COVID-19. Despite having moderate to high levels of psychological distress and fear, more than half of the participants (57\%) reported medium to high levels of resilient coping.

Findings from this study were consistent with the previous Australian study [9]. Similarly, the previous research found almost a third of the participants (33\%) experienced high to very high levels of psychological distress; however, they found more participants experienced a high level of fear of COVID-19 (32\%), while our study found only 24\%. Furthermore, the Australian study found that almost all participants (97\%) had low resilient coping, whereas this global study found $57 \%$ participants 
Table 2 Predictors for psychological distress among the study participants (based on the K-10 score)

\begin{tabular}{|c|c|c|c|c|c|c|c|c|c|c|}
\hline \multirow[t]{2}{*}{ Characteristics } & \multicolumn{2}{|c|}{$\begin{array}{l}\text { Low (score } \\
10-15)\end{array}$} & \multicolumn{2}{|c|}{$\begin{array}{l}\text { Moderate to Very } \\
\text { High (score 16-50) }\end{array}$} & \multicolumn{3}{|c|}{ Unadjusted analyses } & \multicolumn{3}{|c|}{ Adjusted analyses } \\
\hline & $n$ & $\%$ & $\mathrm{n}$ & $\%$ & $p$ & ORs & $95 \% \mathrm{Cls}$ & $p$ & AORs & $95 \% \mathrm{Cls}$ \\
\hline Age groups & 2434 & 32.1 & 5157 & 67.9 & & & & & & \\
\hline $18-29$ years & 775 & 21.1 & 2884 & 78.8 & Ref & & & Ref & & \\
\hline $30-59$ & 1429 & 39.7 & 2170 & 60.3 & $<0.001$ & 0.41 & $0.37-0.45$ & $<0.001$ & 0.50 & $0.41-0.61$ \\
\hline$\geq 60$ years & 230 & 69.1 & 103 & 30.9 & $<0.001$ & 0.12 & $0.08-0.15$ & $<0.001$ & 0.15 & $0.09-0.23$ \\
\hline Gender & 2622 & 31.1 & 5810 & 68.9 & & & & & & \\
\hline Male & 1100 & 36.7 & 1898 & 63.3 & Ref & & & Ref & & \\
\hline Female & 1522 & 28 & 3912 & 71.9 & $<0.001$ & 1.50 & $1.36-1.64$ & 0.003 & 1.31 & $1.09-1.57$ \\
\hline Born in the same country of residence & 2611 & 31 & 5807 & 68.9 & & & & & & \\
\hline No & 421 & 32.7 & 864 & 67.2 & Ref & & & Ref & & \\
\hline Yes & 2190 & 30.7 & 4943 & 69.3 & 0.118 & 1.06 & $0.96-1.18$ & 0.193 & 1.18 & $0.92-1.52$ \\
\hline Living status & 2609 & 31.1 & 5790 & 68.9 & & & & & & \\
\hline Live without family members & 608 & 32.1 & 1289 & 67.9 & Ref & & & Ref & & \\
\hline Live with family members & 2001 & 30.9 & 4501 & 69.2 & 0.133 & 1.09 & $0.97-1.24$ & 0.064 & 1.25 & $0.99-1.56$ \\
\hline Highest educational/vocational qualification & 2603 & 30.9 & 5803 & 69.03 & & & & & & \\
\hline Primary/Grade 1 to 6 & 20 & 33.9 & 39 & 66.1 & Ref & & & Ref & & \\
\hline Secondary/Higher Secondary/Grade 7 to 12 & 373 & 24.2 & 1168 & 75.8 & 0.100 & 1.61 & $0.91-2.83$ & 0.375 & 0.53 & $0.13-2.14$ \\
\hline Certificate/Diploma/Trade qualifications & 269 & 30.9 & 601 & 68.1 & 0.605 & 1.16 & $0.65-2.06$ & 0.231 & 0.43 & $0.11-1.72$ \\
\hline Bachelor/Masters/PhD & 1941 & 32.7 & 3995 & 67.3 & 0.848 & 1.06 & $0.61-1.84$ & 0.247 & 0.44 & $0.11-1.75$ \\
\hline Current employment condition & 2565 & 31.4 & 5597 & 68.5 & & & & & & \\
\hline $\begin{array}{l}\text { Unemployed/Housewife/Home maker/Home duties (No source } \\
\text { of income) }\end{array}$ & 242 & 37.6 & 401 & 62.4 & Ref & & & Ref & & \\
\hline $\begin{array}{l}\text { Jobs affected by COVID-19 (lost job/working hours reduced/afraid } \\
\text { of job loss) }\end{array}$ & 1499 & 36.4 & 2623 & 63.6 & 0.481 & 1.06 & $0.89-1.26$ & $\begin{array}{l}\text { No estim } \\
\text { number }\end{array}$ & tes due tc & small \\
\hline Have an income source (employed/Government benefits) & 824 & 24.3 & 2573 & 75.4 & $<0.001$ & 1.88 & $1.58-2.25$ & 0.003 & 1.35 & $1.10-1.63$ \\
\hline Perceived distress due to change of employment status & 2317 & 30.5 & 5300 & 69.6 & & & & & & \\
\hline A little to none & 1735 & 36.8 & 2970 & 63.1 & Ref & & & Ref & & \\
\hline Moderate to a great deal & 582 & 19.9 & 2330 & 80.01 & $<0.001$ & 2.38 & 2.1-2.61 & $<0.001$ & 1.56 & $1.29-1.90$ \\
\hline Improved working situation due to change of employment status & 1730 & 29.7 & 4092 & 70.3 & & & & & & \\
\hline A little to none & 1373 & 30.6 & 3100 & 69.3 & Ref & & & Ref & & \\
\hline Moderate to a great deal & 357 & 26.5 & 992 & 73.5 & 0.022 & 1.23 & $1.07-1.41$ & 0.723 & 0.97 & $0.80-1.18$ \\
\hline Self-identification as a frontline or essential service worker & 2621 & 31.1 & 5823 & 68.9 & & & & & & \\
\hline No & 1588 & 31.6 & 3437 & 68.4 & Ref & & & Ref & & \\
\hline Yes & 1033 & 30.2 & 2386 & 69.7 & 0.084 & 1.07 & $0.98-1.19$ & 0.830 & 0.98 & $0.79-1.21$ \\
\hline Self-identification as a healthcare worker & 1874 & 29.8 & 4416 & 70.2 & & & & & & \\
\hline No & 1072 & 27.8 & 2771 & 72.1 & Ref & & & Ref & & \\
\hline Yes, doctor & 261 & 29.4 & 626 & 70.6 & 0.291 & 0.92 & $0.78-1.08$ & 0.028 & 1.43 & 1.04-1.97 \\
\hline Yes, nurse & 395 & 38.3 & 637 & 61.7 & $<0.001$ & 0.63 & $0.54-0.72$ & 0.375 & 1.13 & $0.86-1.5$ \\
\hline Yes, other healthcare worker & 146 & 27.6 & 382 & 72.4 & 0.893 & 1.01 & $0.82-1.25$ & 0.521 & 1.11 & $0.81-1.52$ \\
\hline COVID-19 impacted financial situation & 2634 & 31.1 & 5845 & 68.9 & & & & & & \\
\hline No impact & 1479 & 39.2 & 2297 & 60.8 & Ref & & & Ref & & \\
\hline Yes, impacted positively & 292 & 28.7 & 725 & 71.3 & $<0.001$ & 1.59 & $1.37-1.86$ & 0.330 & 1.14 & $0.88-1.48$ \\
\hline Yes, impacted negatively & 863 & 23.4 & 2823 & 76.6 & $<0.001$ & 2.10 & $1.89-2.32$ & 0.770 & 1.03 & $0.84-1.27$ \\
\hline Affected by the change in financial situation & 1814 & 29.6 & 4308 & 70.4 & & & & & & \\
\hline Not at all & 690 & 49.4 & 707 & 50.6 & Ref & & & Ref & & \\
\hline Unsure & 268 & 29.4 & 644 & 70.6 & $<0.001$ & 2.35 & $1.96-2.80$ & $<0.001$ & 1.69 & $1.32-2.16$ \\
\hline Somewhat & 710 & 25.6 & 2060 & 74.4 & $<0.001$ & 2.83 & $2.47-3.24$ & $<0.001$ & 1.64 & $1.32-2.03$ \\
\hline A great extent & 146 & 14 & 897 & 86 & $<0.001$ & 5.99 & 4.89-7.35 & $<0.001$ & 2.36 & $1.72-3.23$ \\
\hline
\end{tabular}


Table 2 Predictors for psychological distress among the study participants (based on the K-10 score) (Continued)

\begin{tabular}{|c|c|c|c|c|c|c|c|c|c|c|}
\hline \multirow[t]{2}{*}{ Characteristics } & \multicolumn{2}{|c|}{$\begin{array}{l}\text { Low (score } \\
10-15)\end{array}$} & \multicolumn{2}{|c|}{$\begin{array}{l}\text { Moderate to Very } \\
\text { High (score 16-50) }\end{array}$} & \multicolumn{3}{|c|}{ Unadjusted analyses } & \multicolumn{3}{|c|}{ Adjusted analyses } \\
\hline & $\mathrm{n}$ & $\%$ & $n$ & $\%$ & $\mathrm{p}$ & ORs & $95 \% \mathrm{Cls}$ & $p$ & AORs & $95 \% \mathrm{Cls}$ \\
\hline Co-morbidities & 2601 & 31.1 & 5770 & 68.9 & & & & & & \\
\hline No & 1926 & 32.3 & 4020 & 67.6 & Ref & & & Ref & & \\
\hline Psychiatric/Mental health problem & 31 & 8.7 & 327 & 91.3 & $<0.001$ & 5.04 & $3.47-7.32$ & 0.019 & 3.02 & $1.20-7.60$ \\
\hline Other co-morbidities* & 644 & 31.2 & 1423 & 68.8 & 0.436 & 1.04 & $0.94-1.17$ & 0.147 & 1.30 & $0.91-1.82$ \\
\hline Co-morbidities & 2465 & 30.9 & 5502 & 69.1 & & & & & & \\
\hline No & 1926 & 32.4 & 4020 & 67.6 & Ref & & & Ref & & \\
\hline Single co-morbidity & 411 & 26.6 & 1136 & 73.4 & 0.001 & 1.32 & $1.17-1.50$ & 0.859 & 0.97 & $0.67-1.40$ \\
\hline Multiple co-morbidities & 128 & 27 & 346 & 73 & 0.114 & 1.30 & $1.05-1.60$ & $\begin{array}{l}\text { No estim } \\
\text { number }\end{array}$ & tes due & small \\
\hline Perceived status of own mental health & 1874 & 29.8 & 4416 & 70.2 & & & & & & \\
\hline Poor to Fair & 131 & 7.5 & 1622 & 92.5 & Ref & & & Ref & & \\
\hline Good to Excellent & 1743 & 38.4 & 2794 & 61.6 & $<0.001$ & 0.13 & $0.11-0.16$ & $<0.001$ & 0.17 & $0.13-0.22$ \\
\hline Smoking & 2634 & 31.1 & 5846 & 68.9 & & & & & & \\
\hline Never smoker & 2226 & 32.3 & 4668 & 67.6 & Ref & & & Ref & & \\
\hline Ever smoker (Daily/Non-daily/Ex) & 408 & 25.7 & 1178 & 74.3 & $<0.001$ & 1.38 & $1.22-1.56$ & 0.434 & 1.10 & $0.87-1.39$ \\
\hline Increased smoking over the last 6 months & 206 & 20.3 & 808 & 79.7 & & & & & & \\
\hline No & 151 & 28.2 & 384 & 71.9 & Ref & & & \multirow{2}{*}{\multicolumn{3}{|c|}{$\begin{array}{l}\text { Not included in multivariate } \\
\text { model }\end{array}$}} \\
\hline Yes & 55 & 11.5 & 424 & 88.5 & $<0.000$ & 3.03 & $2.16-4.25$ & & & \\
\hline Current alcohol drinking (last 4 weeks) & 2583 & 30.9 & 5755 & 69.02 & & & & & & \\
\hline No & 2314 & 31.2 & 5104 & 68.7 & Ref & & & Ref & & \\
\hline Yes & 269 & 29.2 & 651 & 70.7 & 0.199 & 1.10 & $0.95-1.28$ & 0.069 & 1.29 & $0.99-1.68$ \\
\hline Increased alcohol drinking over the last 6 months & 266 & 29.2 & 645 & 70.8 & & & & & & \\
\hline No & 235 & 36.9 & 404 & 63.2 & Ref & & & \multirow{2}{*}{\multicolumn{3}{|c|}{$\begin{array}{l}\text { Not included in multivariate } \\
\text { model }\end{array}$}} \\
\hline Yes & 31 & 11.4 & 241 & 88.6 & $<0.001$ & 4.52 & $3.01-6.80$ & & & \\
\hline Contact with known/suspected case of COVID-19 & 2574 & 30.9 & 5743 & 69.1 & & & & & & \\
\hline No & 1754 & 35.9 & 3127 & 64.1 & Ref & & & Ref & & \\
\hline Unsure & 141 & 19.9 & 567 & 80.1 & $<0.001$ & 2.26 & $1.85-2.73$ & $<0.001$ & 1.80 & $1.36-2.40$ \\
\hline Yes, had indirect contact & 223 & 23.4 & 729 & 76.5 & $<0.001$ & 1.83 & $1.55-2.16$ & 0.019 & 1.32 & $1.04-1.67$ \\
\hline Yes, provided direct care & 456 & 25.6 & 1320 & 74.3 & $<0.001$ & 1.63 & $1.44-1.85$ & 0.814 & 1.03 & $0.81-1.30$ \\
\hline Experience related to COVID-19 pandemic & 2518 & 30.9 & 5631 & 69.1 & & & & & & \\
\hline No known exposure to COVID-19 & 2095 & 33.2 & 4224 & 66.8 & Ref & & & Ref & & \\
\hline Tested positive for COVID-19 & 124 & 25.2 & 369 & 74.8 & $<0.001$ & 1.48 & $1.2-1.82$ & 0.988 & 1.00 & $0.72-1.38$ \\
\hline Tested negative for COVID-19 by self-isolated & 256 & 22.6 & 876 & 77.3 & $<0.001$ & 1.69 & $1.45-1.97$ & 0.086 & 1.24 & $0.97-1.58$ \\
\hline Had recent overseas travel history and was in quarantine & 43 & 20.9 & 162 & 79.02 & 0.002 & 1.87 & $1.32-2.62$ & 0.696 & 1.12 & $0.64-1.93$ \\
\hline $\begin{array}{l}\text { Self-identification as a patient (visited a healthcare provider in } \\
\text { the last } 6 \text { months) }\end{array}$ & 2579 & 31.1 & 5719 & 68.9 & & & & & & \\
\hline No & 1945 & 35.1 & 3606 & 64.9 & Ref & & & Ref & & \\
\hline Yes & 634 & 23.1 & 2113 & 76.9 & $<0.001$ & 1.80 & $1.61-2.00$ & $<0.001$ & 1.67 & $1.40-1.99$ \\
\hline Healthcare service use in the last 6 months & 646 & 23.7 & 2079 & 76.3 & & & & & & \\
\hline In-person visit to a healthcare provider & 493 & 26.1 & 1401 & 73.9 & Ref & & & Ref & & \\
\hline Telehealth consultation/Use of national helpline & 120 & 18.9 & 516 & 81.1 & $<0.001$ & 1.51 & $1.21-1.89$ & \multirow{2}{*}{\multicolumn{3}{|c|}{$\begin{array}{l}\text { Not included in multivariate } \\
\text { model }\end{array}$}} \\
\hline Used both services & 33 & 16.9 & 162 & 83.1 & 0.005 & 1.72 & $1.17-2.54$ & & & \\
\hline Level of fear of COVID-19 (FCV-19S categories) & 2634 & 31.1 & 5845 & 68.9 & & & & & & \\
\hline Low (score 7-21) & 2328 & 36.3 & 4088 & 63.7 & Ref & & & Ref & & \\
\hline High (score 22-35) & 306 & 14.8 & 1757 & 85.2 & $<0.001$ & 3.27 & 2.87-3.73 & $<0.001$ & 3.26 & 2.57-4.13 \\
\hline Level of coping (BRCS categories) & 2633 & 31.1 & 5840 & 68.9 & & & & & & \\
\hline Low resilient copers (score 4-13) & 1011 & 27.6 & 2648 & 72.4 & Ref & & & Ref & & \\
\hline
\end{tabular}


Table 2 Predictors for psychological distress among the study participants (based on the K-10 score) (Continued)

\begin{tabular}{|c|c|c|c|c|c|c|c|c|c|c|}
\hline \multirow[t]{2}{*}{ Characteristics } & \multicolumn{2}{|c|}{$\begin{array}{l}\text { Low (score } \\
10-15)\end{array}$} & \multicolumn{2}{|c|}{$\begin{array}{l}\text { Moderate to Very } \\
\text { High (score } 16-50 \text { ) }\end{array}$} & \multicolumn{3}{|c|}{ Unadjusted analyses } & \multicolumn{3}{|c|}{ Adjusted analyses } \\
\hline & $\mathrm{n}$ & $\%$ & $\mathrm{n}$ & $\%$ & $\mathrm{p}$ & ORs & $95 \% \mathrm{Cls}$ & $\bar{p}$ & AORs & $95 \% \mathrm{Cls}$ \\
\hline Medium to high resilient copers (score 14-20) & 1622 & 33.7 & 3192 & 66.3 & $<0.001$ & 0.75 & $0.69-0.82$ & 0.637 & 0.96 & $0.81-1.14$ \\
\hline $\begin{array}{l}\text { Healthcare service use to overcome COVID-19 related stress in } \\
\text { the last } 6 \text { months }\end{array}$ & 2560 & 31 & 5697 & 69 & & & & & & \\
\hline No & 2422 & 33.7 & 4754 & 66.3 & Ref & & & Ref & & \\
\hline Yes & 138 & 12.8 & 943 & 69 & $<0.001$ & 3.48 & 2.89-4.19 & $<0.001$ & 1.99 & $1.45-2.72$ \\
\hline
\end{tabular}

Adjusted for: age, gender, smoking, alcohol intake, living status, place of birth, country, education, employment status, employment stress, healthcare worker, financial impact, contact with COVID-19 case, experience due to COVID-19 and self-identification as a patient

had medium to high resilient coping. Learning from previous successful experiences that enable people to cope better could explain this discrepancy [17]. When participants from the Australian study were faced with COVID-19 at an earlier stage, participants of this study (that included participants who were confronted with both $1^{\text {st }}$ and $2^{\text {nd }}$ waves) might have learned how to cope with all kinds of relevant practices from the $1^{\text {st }}$ wave of the pandemic (such as social distancing, home quarantine, or lockdown, hand hygiene and wearing masks), leading them to high resilient coping and less fear of COVID-19. However, the context was interplayed with distress and fear in this study. It was found that participants who perceived distress due to change of their employment, whose financial situation was affected greatly, and had unsure contact with COVID-19 were more likely to have higher psychological distress and fear.

We found that females had higher psychological distress and fear of COVID-19. This finding is consistent with the Australian study, [9] and studies from elsewhere [18]. They also had a greater chance of loneliness, specifically for young people aged 18-29 years or those $60+[19]$. Such distress and fear could also be related to 'infodemic' through the increased use of social media [20]. Having a history of mental illness and experience of family violence was shown to aggravate depression, anxiety and stress amongst women during the pandemic [21]. In addition, concerns of exposure to COVID-19 amongst family members could have accentuated their anxiety and distress. Women tend to have more care giving roles in a family and often prioritise health concerns of family members over their own [9]. That warrants improved awareness amongst women regarding regular health assessment and accessing resources to support their wellbeing.

Interestingly, participants who perceived their mental health as good to excellent, even though their financial situation was impacted negatively, and who had contact with COVID-19 patients indirectly or directly were more likely to have medium to high resilient coping. This was especially true for participants who self-identified themselves as nurses. This is incongruent with the Australian study, though consistent with earlier studies [22]. Our findings reflected that participants perceived mental resiliency could be the internal psychological aid that eases their reality during the pandemic despite having higher psychological distress. Enhancing resilience could be a possible intervention to enable people to cope with the mental health impact of COVID-19. Such a psychological resilience model has been developed and tested for its effectiveness in China and was found to improve the overall mental health of the target population during the COVID-19 pandemic [23].

In our study, doctors had higher psychological distress, but low levels of fear of COVID-19; nurses had medium to high resilient coping. A recent systematic review of 24 studies with 13,731 health and social care workers showed that female nurses, comorbidities, lack of personal protective equipment, concerns about family, fear of infections and close contact with COVID-19 patients were the predictors for poor mental wellbeing amongst healthcare workers [24]. Low levels of fear amongst the frontline healthcare workers in our study were likely due to their prolonged professional exposure with COVID19 patient management. Due to the heterogeneity of the health systems and varying availability of resources across participating countries, healthcare workers experienced catastrophic situations during the surge of pandemic period, which could have resulted in high resilience amongst the nurses.

Our findings showed that participants who had comorbidities and those who had a mental illness showed higher psychological distress and fear. These groups were more vulnerable under pandemic guidelines (such as social distancing, working from home), which potentially raised the risks of relapse, especially those who were mentally ill and who needed primary caregivers. Generally, evidence from clinical settings and literature indicated that mentally ill persons who lived alone would have more psychotic relapses than those being cared for by primary caregivers [25]. Medication adherence for this group of patients could have been challenging 
Table 3 Predictors for fear of COVID-19 among the study participants (based on the FCV-19S score)

\begin{tabular}{|c|c|c|c|c|c|c|c|c|c|c|}
\hline \multirow[t]{2}{*}{ Characteristics } & \multicolumn{2}{|c|}{$\begin{array}{l}\text { Low (score } \\
7-21)\end{array}$} & \multicolumn{2}{|c|}{$\begin{array}{l}\text { High (score } \\
22-35)\end{array}$} & \multicolumn{3}{|c|}{ Unadjusted analyses } & \multicolumn{3}{|c|}{ Adjusted analyses } \\
\hline & $n$ & $\%$ & $\mathrm{n}$ & $\%$ & $p$ & ORs & $95 \% \mathrm{Cls}$ & $p$ & AORs & $95 \% \mathrm{Cls}$ \\
\hline Age groups & 5710 & 75.20 & 1886 & 24.8 & & & & & & \\
\hline $18-29$ years & 2777 & 75.8 & 883 & 24.1 & Ref & & & Ref & & \\
\hline $30-59$ years & 2661 & 73.8 & 942 & 26.1 & 0.047 & 1.11 & $1.00-1.24$ & 0.004 & 1.35 & $1.10-1.64$ \\
\hline$\geq 60$ years & 272 & 81.6 & 61 & 18.3 & 0.017 & 0.71 & $0.53-0.94$ & 0.184 & 1.40 & $0.86-2.30$ \\
\hline Gender & 6383 & 75.6 & 2055 & 24.4 & & & & & & \\
\hline Male & 2305 & 76.8 & 695 & 23.20 & Ref & & & Ref & & \\
\hline Female & 4078 & 74.9 & 1360 & 25.1 & 0.059 & 1.11 & $0.99-1.23$ & 0.001 & 1.51 & $1.25-1.83$ \\
\hline Born in the same country of residence & 6365 & 75.5 & 2059 & 24.4 & & & & & & \\
\hline No & 933 & 72.4 & 355 & 27.6 & Ref & & & Ref & & \\
\hline Yes & 5432 & 76.1 & 1704 & 23.8 & 0.005 & 0.82 & $0.72-0.94$ & 0.001 & 0.66 & $0.51-0.85$ \\
\hline Living status & 6354 & 75.6 & 2050 & 24.4 & & & & & & \\
\hline Live without family members & 1322 & 69.6 & 577 & 30.4 & Ref & & & Ref & & \\
\hline Live with family members & 5032 & 77.4 & 1473 & 22.6 & $<0.001$ & 0.67 & $0.6-0.75$ & 0.431 & 1.10 & $0.86-1.41$ \\
\hline Highest educational/vocational qualification & 6359 & 75.6 & 2052 & 24.4 & & & & & & \\
\hline Primary/Grade 1 to 6 & 47 & 79.6 & 12 & 20.3 & Ref & & & Ref & & \\
\hline Secondary/Higher Secondary/Grade 7 to 12 & 1176 & 76.3 & 366 & 23.7 & 0.547 & 1.22 & $0.64-2.32$ & 0.569 & 1.41 & $0.44-4.55$ \\
\hline Certificate/Diploma/Trade qualifications & 626 & 71.8 & 245 & 28.1 & 0.198 & 1.53 & $0.8-2.93$ & 0.298 & 1.87 & $0.57-6.09$ \\
\hline Bachelor/Masters/PhD & 4510 & 75.9 & 1429 & 24.1 & 0.506 & 1.24 & $0.66-2.35$ & 0.689 & 1.27 & $0.40-4.05$ \\
\hline Current employment condition & 6174 & 75.6 & 1994 & 24.4 & & & & & & \\
\hline $\begin{array}{l}\text { Unemployed/Housewife/Home maker/Home duties } \\
\text { (No source of income) }\end{array}$ & 433 & 67.3 & 210 & 32.6 & Ref & & & Ref & & \\
\hline $\begin{array}{l}\text { Jobs affected by COVID-19 (lost job/working hours } \\
\text { reduced/afraid of job loss) }\end{array}$ & 3304 & 80.1 & 821 & 19.9 & $<0.001$ & 0.51 & $0.42-0.61$ & No estim & e due to & nall number \\
\hline Have an income source (employed/Government benefits) & 2437 & 71.7 & 963 & 28.3 & 0.026 & 0.81 & $0.68-0.98$ & 0.588 & 1.05 & $0.87-1.27$ \\
\hline Perceived distress due to change of employment status & 5772 & 75.7 & 1847 & 24.2 & & & & & & \\
\hline A little to none & 3767 & 80.1 & 939 & 19.9 & Ref & & & Ref & & \\
\hline Moderate to a great deal & 2005 & 68.8 & 908 & 31.2 & $<0.001$ & 1.82 & $1.63-2.02$ & $<0.001$ & 1.52 & $1.27-1.82$ \\
\hline Improved working situation due to change of employment status & 4570 & 78.5 & 1251 & 21.5 & & & & & & \\
\hline A little to none & 3566 & 79.7 & 906 & 20.3 & Ref & & & Ref & & \\
\hline Moderate to a great deal & 1004 & 74.4 & 345 & 25.6 & $<0.001$ & 1.35 & 1.17-1.56 & 0.401 & 1.08 & $0.9-1.32$ \\
\hline Self-identification as a frontline or essential service worker & 6398 & 75.7 & 2052 & 24.3 & & & & & & \\
\hline No & 3839 & 76.3 & 1191 & 23.7 & Ref & & & Ref & & \\
\hline Yes & 2559 & 74.8 & 861 & 25.2 & 0.115 & 1.08 & $0.99-1.2$ & 0.001 & 1.47 & $1.20-1.82$ \\
\hline Self-identification as a healthcare worker & 4950 & 78.7 & 1339 & 21.3 & & & & & & \\
\hline No & 2990 & 77.8 & 853 & 22.2 & Ref & & & Ref & & \\
\hline Yes, doctor & 712 & 80.4 & 174 & 19.6 & 0.096 & 0.86 & $0.71-1.03$ & $<0.001$ & 0.55 & $0.41-0.76$ \\
\hline Yes, nurse & 838 & 81.2 & 194 & 18.8 & 0.018 & 0.81 & $0.68-0.97$ & 0.053 & 0.75 & $0.56-1.01$ \\
\hline Yes, other healthcare worker & 410 & 77.6 & 118 & 22.4 & 0.937 & 1.01 & $0.81-1.26$ & 0.131 & 0.79 & $0.58-1.07$ \\
\hline COVID-19 impacted financial situation & 6418 & 75.6 & 2066 & 24.4 & & & & & & \\
\hline No impact & 3053 & 80.8 & 725 & 19.2 & Ref & & & Ref & & \\
\hline Yes, impacted positively & 768 & 75.5 & 249 & 24.5 & $<0.001$ & 1.37 & $1.16-1.61$ & 0.075 & 1.29 & $0.98-1.70$ \\
\hline Yes, impacted negatively & 2597 & 70.4 & 1092 & 29.6 & $<0.001$ & 1.77 & $1.6-1.97$ & 0.004 & 1.36 & $1.11-1.68$ \\
\hline Affected by the change in financial situation & 4813 & 78.6 & 1308 & 21.4 & & & & & & \\
\hline Not at all & 1201 & 85.9 & 196 & 14 & Ref & & & Ref & & \\
\hline Unsure & 724 & 79.4 & 188 & 20.6 & $<0.001$ & 1.59 & $1.28-1.98$ & 0.149 & 1.23 & $0.93-1.64$ \\
\hline Somewhat & 2169 & 78.3 & 600 & 21.7 & $<0.001$ & 1.69 & $1.42-2.02$ & 0.033 & 1.32 & $1.02-1.08$ \\
\hline A great extent & 719 & 68.9 & 324 & 31.1 & $<0.001$ & 2.76 & $2.26-3.37$ & 0.021 & 1.44 & $1.06-1.96$ \\
\hline
\end{tabular}


Table 3 Predictors for fear of COVID-19 among the study participants (based on the FCV-19S score) (Continued)

\begin{tabular}{|c|c|c|c|c|c|c|c|c|c|c|}
\hline \multirow[t]{2}{*}{ Characteristics } & \multicolumn{2}{|c|}{$\begin{array}{l}\text { Low (score } \\
7-21)\end{array}$} & \multicolumn{2}{|c|}{$\begin{array}{l}\text { High (score } \\
\text { 22-35) }\end{array}$} & \multicolumn{3}{|c|}{ Unadjusted analyses } & \multicolumn{3}{|c|}{ Adjusted analyses } \\
\hline & $n$ & $\%$ & $n$ & $\%$ & $p$ & ORs & $95 \% \mathrm{Cls}$ & $p$ & AORs & $95 \% \mathrm{Cls}$ \\
\hline Co-morbidities & 6345 & 75.7 & 2032 & 24.3 & & & & & & \\
\hline No & 4645 & 78.1 & 1303 & 21.9 & Ref & & & Ref & & \\
\hline Psychiatric/Mental health problem & 248 & 68.7 & 113 & 31.3 & $<0.001$ & 1.62 & $1.29-2.05$ & 0.984 & 1.00 & $0.64-1.60$ \\
\hline Other co-morbidities* & 1452 & 70.2 & 616 & 29.8 & $<0.001$ & 1.51 & $1.35-1.7$ & 0.001 & 1.71 & $1.25-2.32$ \\
\hline Co-morbidities & 6059 & 76.1 & 1910 & 23.9 & & & & & & \\
\hline No & 4645 & 78.1 & 1303 & 21.9 & Ref & & & Ref & & \\
\hline Single co-morbidity & 1096 & 70.9 & 451 & 29.2 & $<0.001$ & 1.47 & $1.29-1.66$ & 0.021 & 0.69 & $0.51-0.95$ \\
\hline Multiple co-morbidities & 318 & 67.1 & 156 & 32.9 & $<0.001$ & 1.75 & $1.43-2.14$ & No estim & e due to & nall number \\
\hline Perceived status of own mental health & 4950 & 78.7 & 1339 & 21.3 & & & & & & \\
\hline Poor to Fair & 1190 & 67.9 & 563 & 32.1 & Ref & & & Ref & & \\
\hline Good to Excellent & 3760 & 82.9 & 776 & 17.1 & $<0.001$ & 0.44 & $0.39-0.5$ & $<0.001$ & 0.72 & $0.60-0.86$ \\
\hline Smoking & 6420 & 75.6 & 2065 & 24.3 & & & & & & \\
\hline Never smoker & 5251 & 76.1 & 1647 & 23.8 & Ref & & & Ref & & \\
\hline Ever smoker (Daily/Non-daily/Ex) & 1169 & 73.6 & 418 & 26.3 & 0.039 & 1.14 & $1.01-1.30$ & 0.708 & 1.04 & $0.84-1.31$ \\
\hline Increased smoking over the last 6 months & 758 & 74.7 & 256 & 25.3 & & & & & & \\
\hline No & 418 & 78.1 & 117 & 21.9 & Ref & & & Not inclu & ed in me & variate model \\
\hline Yes & 340 & 70.9 & 139 & 29 & 0.009 & 1.46 & $1.1-1.94$ & & & \\
\hline Current alcohol drinking (last 4 weeks) & 6309 & 75.6 & 2035 & 24.4 & & & & & & \\
\hline No & 5646 & 76.1 & 1776 & 23.9 & Ref & & & Ref & & \\
\hline Yes & 663 & 71.9 & 259 & 28.1 & 0.006 & 1.24 & $1.07-1.45$ & 0.038 & 1.33 & $1.02-1.73$ \\
\hline Increased alcohol drinking over the last 6 months & 658 & 72.1 & 255 & 27.9 & & & & & & \\
\hline No & 511 & 79.7 & 130 & 20.3 & Ref & & & Not inclu & ed in me & variate model \\
\hline Yes & 147 & 54.1 & 125 & 45.9 & $<0.001$ & 3.34 & $2.46-4.54$ & & & \\
\hline Contact with known/suspected case of COVID-19 & 6292 & 75.6 & 2031 & 24.4 & & & & & & \\
\hline No & 3769 & 771 & 1117 & 22.9 & Ref & & & Ref & & \\
\hline Unsure & 488 & 68.8 & 221 & 31.2 & $<0.001$ & 1.53 & $1.29-1.82$ & 0.006 & 1.41 & $1.10-1.80$ \\
\hline Yes, had indirect contact & 722 & 75.8 & 230 & 24.2 & 0.384 & 1.07 & $0.92-1.26$ & 0.713 & 1.04 & $0.86-1.35$ \\
\hline Yes, provided direct care & 1313 & 73.9 & 463 & 26.1 & 0.007 & 1.19 & $1.04-1.35$ & 0.782 & 0.97 & $0.76-1.23$ \\
\hline Experience related to COVID-19 pandemic & 6155 & 75.5 & 2000 & 24.5 & & & & & & \\
\hline No known exposure to COVID-19 & 4833 & 76.4 & 1490 & 23.6 & Ref & & & Ref & & \\
\hline Tested positive for COVID-19 & 391 & 79.2 & 103 & 20.8 & 0.170 & 0.85 & $0.68-1.07$ & 0.175 & 0.80 & $0.57-1.11$ \\
\hline Tested negative for COVID-19 by self-isolated & 791 & 69.8 & 342 & 30.2 & $<0.001$ & 1.40 & $1.22-1.61$ & 0.336 & 1.12 & $0.89-1.41$ \\
\hline Had recent overseas travel history and was in quarantine & 140 & 68.3 & 65 & 31.7 & 0.007 & 1.51 & $1.12-2.03$ & 0.808 & 0.93 & $0.54-1.61$ \\
\hline $\begin{array}{l}\text { Self-identification as a patient (visited a healthcare provider } \\
\text { in the last } 6 \text { months) }\end{array}$ & 6273 & 75.5 & 2031 & 24.5 & & & & & & \\
\hline No & 4247 & 76.5 & 1308 & 23.6 & Ref & & & Ref & & \\
\hline Yes & 2026 & 73.7 & 723 & 26.3 & 0.006 & 1.16 & $1.04-1.29$ & 0.217 & 0.90 & $0.76-1.06$ \\
\hline Healthcare service use in the last 6 months & 1973 & 72.4 & 754 & 27.6 & & & & & & \\
\hline In-person visit to a healthcare provider & 1413 & 74.5 & 483 & 25.5 & Ref & & & Ref & & \\
\hline Telehealth consultation/Use of national helpline & 426 & 66.9 & 210 & 33 & $<0.001$ & 1.44 & 1.19-1.75 & Not inclu & ed in me & variate model \\
\hline Used both services & 134 & 68.7 & 61 & 31.3 & 0.079 & 1.33 & $0.97-1.83$ & & & \\
\hline Level of psychological distress (K10 categories) & 6416 & 75.7 & 2063 & 24.3 & & & & & & \\
\hline Low (score 10-15) & 2328 & 88.4 & 306 & 11.6 & Ref & & & Ref & & \\
\hline Moderate to Very High (score 16-50) & 4088 & 69.9 & 1757 & 30.1 & $<0.001$ & 3.26 & $2.87-3.72$ & $<0.001$ & 3.36 & $2.67-4.23$ \\
\hline Level of coping (BRCS categories) & 6418 & 75.7 & 2061 & 24.3 & & & & & & \\
\hline Low resilient copers (score 4-13) & 2647 & 72.2 & 1018 & 27.8 & Ref & & & Ref & & \\
\hline
\end{tabular}


Table 3 Predictors for fear of COVID-19 among the study participants (based on the FCV-19S score) (Continued)

\begin{tabular}{|c|c|c|c|c|c|c|c|c|c|c|}
\hline \multirow[t]{2}{*}{ Characteristics } & \multicolumn{2}{|c|}{$\begin{array}{l}\text { Low (score } \\
7-21)\end{array}$} & \multicolumn{2}{|c|}{$\begin{array}{l}\text { High (score } \\
\text { 22-35) }\end{array}$} & \multicolumn{3}{|c|}{ Unadjusted analyses } & \multicolumn{3}{|c|}{ Adjusted analyses } \\
\hline & $\mathrm{n}$ & $\%$ & $\mathrm{n}$ & $\%$ & $\mathrm{p}$ & ORs & $95 \% \mathrm{Cls}$ & $\mathrm{p}$ & AORs & $95 \% \mathrm{Cls}$ \\
\hline Medium to high resilient copers (score 14-20) & 3771 & 78.3 & 1043 & 21.7 & $<0.001$ & 0.72 & $0.65-0.80$ & $<0.001$ & 0.74 & $0.63-0.87$ \\
\hline $\begin{array}{l}\text { Healthcare service use to overcome COVID-19 related } \\
\text { stress in the last } 6 \text { months }\end{array}$ & 6243 & 75.6 & 2020 & 24.5 & & & & & & \\
\hline No & 5595 & 77.9 & 1587 & 22.1 & Ref & & & Ref & & \\
\hline Yes & 648 & 59.9 & 433 & 40.1 & $<0.001$ & 2.35 & $2.06-2.70$ & $<0.001$ & 2.42 & $1.96-3.01$ \\
\hline
\end{tabular}

Adjusted for: age, gender, smoking, alcohol intake, living status, place of birth, country, education, employment status, employment stress, healthcare worker, financial impact, contact with COVID-19 case, experience due to COVID-19 and self-identification as a patient

without caregiving provision [26]. Accessibility to the health care system was more difficult because most healthcare workers were overloaded with COVID-19 infected patients and the related tasks, therefore, managing chronic diseases was not a priority. In addition, lockdown policies impacted transportation and public facilities were closed in many instances. Previous evidence also suggested that people with stressful situations and pre-existing medical problems had higher levels of depression and anxiety [27]. Telemedicine to replace face-to-face consultations had been established in many countries including Australia during COVID-19. The effect of such an alternative healthcare delivery system needs to be evaluated further, especially its impact on people with non-communicable diseases and/or mental illness who need continuing care.

Eighty-one percent of the study population were never smokers. Those who smoked and drank alcohol, reported increased use of tobacco and alcohol (47\% and $30 \%$ respectively) in the last six months. Moreover, drinking behavior was also associated with higher levels of fear of COVID-19. The findings were consistent with the previous Australian study and that risky behavior was associated with a higher impact on psychological distress [16]. A study conducted in China also found that participants who had a history of smoking could escalate the severe symptoms of COVID-19 once hospitalized and possibly required ventilator equipment [28]. A Polish study also revealed that current alcohol drinkers were less able to find positives about the pandemic (positive reframing) and coping [29]. An effective coping strategy needs to be developed and implemented to target populations using social media to prevent unhealthy coping behaviors.

The change of employment status and an uncertain financial situation were associated with higher psychological distress and fear. In our study, 51\% participants reported that their jobs were affected by COVID-19, due to losing jobs, reduced working hours, or being afraid of job loss. That was probably one of the significant indicators of mental wellbeing, impacted by COVID-19 on people's socioeconomic status around the globe and consistent with a study conducted among Israeli youths (20-35 years old) [30]. The need for urgent action to support and elevate economic assistance, especially for those whose job was impacted negatively from the pandemic, is critical. While business enterprises were freezing around the globe due to restrictions related to controlling the spread of coronavirus, basic needs are essential, specifically for vulnerable groups to prevent psychological crisis which could potentially lead to suicidal attempts or even suicide.

The impact of COVID-19 on the psychological wellbeing was unprecedented and was different from country to country. Therefore, findings from 17 countries were found to be diverse. In our study, country specific results on psychological distress showed a specific trend. For example, more than two-thirds of the participants reported moderate to very high level of psychological distress who were living in countries with war/conflict (Syria, Palestine, Libya and the Middle East [Saudi Arabia, UAE, Jordan and Kuwait]) followed by South Asia (Pakistan, Nepal and Bangladesh) and least by the participants from South-East Asian countries (Thailand, Hong Kong and Indonesia). However, participants from Oman, Australia and Egypt could not be fitted into any of those categories. It can be assumed that such disparities could be related to geography, access to healthcare, having comorbidities, living in war-torn and conflicting countries [31]. It can be also assumed that uncertainties about COVID-19, its progression and rapid mutation, availability and access to varied range of evidence could also contribute to the report of diverse country-wise findings of moderate to high level of psychological distress. Similar higher levels of anxiety were reported in Hong Kong during the SARS epidemic amongst medicine students and students 
Table 4 Predictors for coping among the study participants (based on the BRCS score)

\begin{tabular}{|c|c|c|c|c|c|c|c|c|c|c|}
\hline \multirow[t]{2}{*}{ Characteristics } & \multicolumn{2}{|c|}{$\begin{array}{l}\text { Low (score } \\
4-13 \text { ) }\end{array}$} & \multicolumn{2}{|c|}{$\begin{array}{l}\text { Medium to } \\
\text { High (score } \\
14-20 \text { ) }\end{array}$} & \multicolumn{3}{|c|}{ Unadjusted analyses } & \multicolumn{3}{|c|}{ Adjusted analyses } \\
\hline & $\bar{n}$ & $\%$ & $\bar{n}$ & $\%$ & $\bar{p}$ & ORs & $95 \% \mathrm{Cls}$ & $\bar{p}$ & AORs & $95 \% \mathrm{Cls}$ \\
\hline Age groups & 3247 & 42.8 & 4344 & 57.2 & & & & & & \\
\hline $18-29$ years & 1581 & 43.3 & 2074 & 56.7 & Ref & & & Ref & & \\
\hline $30-59$ years & 1543 & 42.8 & 2060 & 57.2 & 0.711 & 1.02 & $0.93-1.12$ & 0.329 & 1.08 & $0.92-1.28$ \\
\hline$\geq 60$ years & 123 & 36.9 & 210 & 63.1 & 0.026 & 1.30 & $1.03-1.64$ & 0.011 & 1.66 & $1.12-2.44$ \\
\hline Gender & 3640 & 43.2 & 4792 & 56.8 & & & & & & \\
\hline Male & 1323 & 44.1 & 1675 & 55.9 & Ref & & & Ref & & \\
\hline Female & 2317 & 42.6 & 3117 & 57.4 & 0.186 & 1.07 & $0.97-1.17$ & 0.235 & 0.91 & $0.79-1.06$ \\
\hline Born in the same country of residence & 3635 & 43.2 & 4783 & 56.8 & & & & & & \\
\hline No & 649 & 50.4 & 639 & 49.6 & Ref & & & Ref & & \\
\hline Yes & 2986 & 41.8 & 4144 & 58.1 & $<0.001$ & 1.41 & $1.25-1.59$ & 0.124 & 0.85 & $0.69-1.05$ \\
\hline Living status & 3614 & 43 & 4784 & 56.9 & & & & & & \\
\hline Live without family members & 812 & 42.7 & 1087 & 57.2 & Ref & & & Ref & & \\
\hline Live with family members & 2802 & 43.1 & 3697 & 56.9 & 0.780 & 0.99 & $0.89-1.1$ & 0.106 & 0.85 & $0.7-1.04$ \\
\hline Highest educational/vocational qualification & 3622 & 43.1 & 4783 & 56.9 & & & & & & \\
\hline Primary/Grade 1 to 6 & 30 & 50.8 & 29 & 49.2 & Ref & & & Ref & & \\
\hline Secondary/Higher Secondary/Grade 7 to 12 & 673 & 43.7 & 868 & 56.3 & 0.277 & 1.33 & $0.8-2.24$ & 0.537 & 1.35 & $0.52-3.48$ \\
\hline Certificate/Diploma/Trade qualifications & 409 & 47.2 & 458 & 57.7 & 0.585 & 1.16 & $0.69-1.96$ & 0.871 & 1.08 & $0.42-2.81$ \\
\hline Bachelor/Masters/PhD & 2510 & 42.3 & 3428 & 57.7 & 0.187 & 1.41 & $0.85-2.36$ & 0.583 & 1.30 & $0.51-3.32$ \\
\hline Current employment condition & 3523 & 43.2 & 4639 & 56.8 & & & & & & \\
\hline Unemployed/Housewife/Home maker/Home duties (No source of income) & 260 & 40.4 & 383 & 59.5 & Ref & & & Ref & & \\
\hline Jobs affected by COVID-19 (lost job/working hours reduced/afraid of job loss) & 1734 & 42.1 & 2391 & 57.9 & 0.444 & 0.94 & $0.797-1.11$ & $\begin{array}{l}\text { No estim } \\
\text { number }\end{array}$ & ate due tc & small \\
\hline Have an income source (employed/Government benefits) & 1529 & 45.1 & 1865 & 54.9 & 0.031 & 0.84 & $0.69-0.99$ & 0.354 & 0.93 & $0.8-1.09$ \\
\hline Perceived distress due to change of employment status & 3095 & 40.6 & 4522 & 59.4 & & & & & & \\
\hline A little to none & 1815 & 38.6 & 2889 & 61.4 & Ref & & & Ref & & \\
\hline Moderate to a great deal & 1280 & 43.9 & 1633 & 56.1 & $<0.001$ & 0.80 & $0.73-0.88$ & 0.030 & 0.82 & $0.68-0.98$ \\
\hline Improved working situation due to change of employment status & 2291 & 39.4 & 3528 & 60.6 & & & & & & \\
\hline A little to none & 1753 & 39.2 & 2717 & 60.8 & Ref & & & Ref & & \\
\hline Moderate to a great deal & 538 & 39.8 & 811 & 60.1 & 0.662 & 0.98 & $0.86-1.1$ & 0.342 & 1.09 & $0.92-1.28$ \\
\hline Self-identification as a frontline or essential service worker & 3646 & 43.2 & 4798 & 56.8 & & & & & & \\
\hline No & 2155 & 42.9 & 2869 & 57.1 & Ref & & & Ref & & \\
\hline Yes & 1491 & 43.6 & 1929 & 56.4 & 0.522 & 0.97 & $0.87-1.06$ & 0.525 & 0.94 & $0.8-1.13$ \\
\hline Self-identification as a healthcare worker & 2482 & 39.5 & 3801 & 60.5 & & & & & & \\
\hline No & 1578 & 41.1 & 2259 & 58.9 & Ref & & & Ref & & \\
\hline Yes, doctor & 331 & 37.4 & 555 & 62.6 & 0.040 & 1.17 & $1.01-1.36$ & 0.417 & 0.90 & $0.70-1.16$ \\
\hline Yes, nurse & 371 & 35.9 & 661 & 64.1 & 0.003 & 1.24 & $1.08-1.44$ & 0.029 & 1.30 & $1.03-1.65$ \\
\hline Yes, other healthcare worker & 202 & 38.3 & 326 & 61.7 & 0.209 & 1.13 & $0.94-1.36$ & 0.280 & 1.15 & $0.90-1.48$ \\
\hline COVID-19 impacted financial situation & 3663 & 43.2 & 4815 & 56.8 & & & & & & \\
\hline No impact & 1613 & 42.8 & 2160 & 57.3 & Ref & & & Ref & & \\
\hline Yes, impacted positively & 413 & 40.7 & 603 & 59.4 & 0.229 & 1.10 & $0.95-1.26$ & 0.851 & 0.98 & $0.80-1.23$ \\
\hline Yes, impacted negatively & 1637 & 44.4 & 2052 & 55.6 & 0.157 & 0.94 & $0.85-1.03$ & $<0.001$ & 1.37 & $1.16-1.62$ \\
\hline Affected by the change in financial situation & 2403 & 39.3 & 3712 & 60.7 & & & & & & \\
\hline Not at all & 523 & 37.4 & 874 & 62.6 & Ref & & & Ref & & \\
\hline Unsure & 385 & 42.4 & 523 & 57.6 & 0.017 & 0.81 & $0.69-0.96$ & 0.004 & 0.74 & $0.60-0.90$ \\
\hline Somewhat & 1051 & 37.9 & 1716 & 62 & 0.732 & 0.98 & $0.86-1.12$ & 0.398 & 0.92 & $0.78-1.14$ \\
\hline A great extent & 444 & 42.6 & 599 & 57.4 & 0.010 & 0.81 & $0.69-0.95$ & 0.151 & 0.83 & $0.66-1.07$ \\
\hline
\end{tabular}


Table 4 Predictors for coping among the study participants (based on the BRCS score) (Continued)

\begin{tabular}{|c|c|c|c|c|c|c|c|c|c|c|}
\hline \multirow[t]{2}{*}{ Characteristics } & \multicolumn{2}{|c|}{$\begin{array}{l}\text { Low (score } \\
4-13)\end{array}$} & \multicolumn{2}{|c|}{$\begin{array}{l}\text { Medium to } \\
\text { High (score } \\
14-20)\end{array}$} & \multicolumn{3}{|c|}{ Unadjusted analyses } & \multicolumn{3}{|c|}{ Adjusted analyses } \\
\hline & $\bar{n}$ & $\%$ & $\bar{n}$ & $\%$ & $\bar{p}$ & ORs & $95 \% \mathrm{Cls}$ & $\bar{p}$ & AORs & $95 \% \mathrm{Cls}$ \\
\hline Co-morbidities & 3630 & 43.4 & 4741 & 56.6 & & & & & & \\
\hline No & 2458 & 41.4 & 3488 & 58.7 & Ref & & & Ref & & \\
\hline Psychiatric/Mental health problem & 223 & 62.5 & 134 & 37.5 & $<0.001$ & 0.42 & $0.33-0.52$ & 0.431 & 0.85 & $0.57-1.27$ \\
\hline Other co-morbidities* & 949 & 45.9 & 1119 & 54.1 & $<0.001$ & 0.82 & $0.73-0.91$ & 0.324 & 1.15 & $0.88-1.50$ \\
\hline Co-morbidities & 3321 & 41.7 & 4642 & 58.3 & & & & & & \\
\hline No & 2458 & 41.3 & 3488 & 58.7 & Ref & & & Ref & & \\
\hline Single co-morbidity & 674 & 43.6 & 873 & 56.4 & 0.113 & 0.91 & $0.81-1.02$ & 0.149 & 0.82 & $0.62-1.09$ \\
\hline Multiple co-morbidities & 189 & 40.2 & 281 & 59.8 & 0.633 & 1.05 & $0.87-1.27$ & $\begin{array}{l}\text { No estim } \\
\text { number }\end{array}$ & ate due & small \\
\hline Perceived status of own mental health & 2482 & 39.5 & 3801 & 60.5 & & & & & & \\
\hline Poor to Fair & 913 & 52.1 & 839 & 47.8 & Ref & & & Ref & & \\
\hline Good to Excellent & 1569 & 34.6 & 2962 & 65.4 & $<0.001$ & 2.05 & $1.83-2.3$ & $<0.001$ & 1.97 & $1.70-2.30$ \\
\hline Smoking & 3665 & 43.2 & 4814 & 56.8 & & & & & & \\
\hline Never smoker & 2912 & 42.2 & 3982 & 57.8 & Ref & & & Ref & & \\
\hline Ever smoker (Daily/Non-daily/Ex) & 753 & 47.5 & 832 & 52.5 & $<0.001$ & 0.81 & $0.72-0.90$ & 0.533 & 1.06 & $0.88-1.28$ \\
\hline Increased smoking over the last 6 months & 447 & 44.2 & 565 & 55.8 & & & & & & \\
\hline No & 234 & 43.7 & 301 & 56.3 & Ref & & & Ref & & \\
\hline Yes & 213 & 44.6 & 264 & 55.4 & 0.770 & 0.96 & $0.75-1.23$ & $\begin{array}{l}\text { Not inclu } \\
\text { model }\end{array}$ & ded in $n$ & llivariate \\
\hline Current alcohol drinking (last 4 weeks) & 3595 & 43.1 & 4743 & 56.8 & & & & & & \\
\hline No & 3089 & 41.6 & 4328 & 58.4 & Ref & & & Ref & & \\
\hline Yes & 506 & 54.9 & 415 & 45.1 & $<0.001$ & 0.59 & $0.50-0.66$ & 0.532 & 0.93 & $0.74-1.17$ \\
\hline Increased alcohol drinking over the last 6 months & 499 & 54.7 & 413 & 45.3 & & & & & & \\
\hline No & 310 & 48.4 & 330 & 51.7 & Ref & & & \multirow{2}{*}{\multicolumn{3}{|c|}{$\begin{array}{l}\text { Not included in multivariate } \\
\text { model }\end{array}$}} \\
\hline Yes & 189 & 69.5 & 83 & 30.5 & $<0.001$ & 0.40 & $0.31-0.56$ & & & \\
\hline Contact with known/suspected case of COVID-19 & 3578 & 43 & 4739 & 56.9 & & & & & & \\
\hline No & 2223 & 45.5 & 2662 & 54.5 & Ref & & & Ref & & \\
\hline Unsure & 333 & 46.9 & 376 & 53 & 0.470 & 0.94 & $0.81-1.1$ & 0.297 & 0.90 & $0.73-1.1$ \\
\hline Yes, had indirect contact & 353 & 37.3 & 594 & 62.7 & $<0.001$ & 1.41 & $1.21-1.63$ & 0.004 & 1.33 & $1.10-1.62$ \\
\hline Yes, provided direct care & 669 & 37.7 & 1107 & 62.3 & $<0.001$ & 1.37 & $1.22-1.53$ & $<0.001$ & 1.45 & 1.19-1.77 \\
\hline Experience related to COVID-19 pandemic & 3497 & 42.9 & 4652 & 57.1 & & & & & & \\
\hline No known exposure to COVID-19 & 2739 & 43.4 & 3580 & 56.6 & Ref & & & Ref & & \\
\hline Tested positive for COVID-19 & 184 & 37.3 & 310 & 62.7 & 0.008 & 1.29 & $1.07-1.56$ & 0.259 & 0.86 & $0.65-1.12$ \\
\hline Tested negative for COVID-19 by self-isolated & 480 & 42.4 & 651 & 57.6 & 0.571 & 1.03 & $0.91-1.18$ & 0.012 & 0.78 & $0.64-0.95$ \\
\hline Had recent overseas travel history and was in quarantine & 94 & 45.8 & 111 & 54.2 & 0.476 & 0.90 & $0.68-1.2$ & 0.312 & 0.80 & $0.51-1.24$ \\
\hline $\begin{array}{l}\text { Self-identification as a patient (visited a healthcare } \\
\text { provider in the last } 6 \text { months) }\end{array}$ & 3564 & 42.9 & 4734 & 57.1 & & & & & & \\
\hline No & 2466 & 44.4 & 3089 & 55.6 & Ref & & & Ref & & \\
\hline Yes & 1098 & 40.1 & 1645 & 59.9 & 0.001 & 1.20 & $1.09-1.31$ & 0.012 & 1.20 & $1.04-1.28$ \\
\hline Healthcare service use in the last 6 months & 1089 & 40 & 1633 & 59.9 & & & & & & \\
\hline In-person visit to a healthcare provider & 730 & 38.5 & 1165 & 61.5 & Ref & & & Ref & & \\
\hline Telehealth consultation/Use of national helpline & 277 & 43.5 & 359 & 56.5 & 0.025 & 0.82 & $0.67-0.97$ & \multirow{2}{*}{\multicolumn{3}{|c|}{$\begin{array}{l}\text { Not included in multivariate } \\
\text { model }\end{array}$}} \\
\hline Used both services & 82 & 42.9 & 109 & 57.1 & 0.234 & 0.83 & $0.62-1.13$ & & & \\
\hline Level of psychological distress (K10 categories) & 3659 & 43.2 & 4814 & 56.8 & & & & & & \\
\hline Low (score 10-15) & 1011 & 38.4 & 1622 & 61.6 & Ref & & & Ref & & \\
\hline Moderate to Very High (score 16-50) & 2648 & 45.4 & 3192 & 54.6 & $<0.001$ & 0.74 & $0.67-0.81$ & 0.498 & 0.95 & $0.81-1.11$ \\
\hline
\end{tabular}


Table 4 Predictors for coping among the study participants (based on the BRCS score) (Continued)

\begin{tabular}{|c|c|c|c|c|c|c|c|c|c|c|}
\hline \multirow[t]{2}{*}{ Characteristics } & \multicolumn{2}{|c|}{$\begin{array}{l}\text { Low (score } \\
4-13 \text { ) }\end{array}$} & \multicolumn{2}{|c|}{$\begin{array}{l}\text { Medium to } \\
\text { High (score } \\
14-20 \text { ) }\end{array}$} & \multicolumn{3}{|c|}{ Unadjusted analyses } & \multicolumn{3}{|c|}{ Adjusted analyses } \\
\hline & $\mathrm{n}$ & $\%$ & $\mathrm{n}$ & $\%$ & $\bar{p}$ & ORs & $95 \% \mathrm{Cls}$ & $\bar{p}$ & AORs & $95 \% \mathrm{Cls}$ \\
\hline Level of fear of COVID-19 (FCV-19S categories) & 3665 & 43.2 & 4814 & 56.7 & & & & & & \\
\hline Low (score 7-21) & 2647 & 41.2 & 3771 & 58.8 & Ref & & & Ref & & \\
\hline High (score 22-35) & 1018 & 49.4 & 1043 & 50.6 & $<0.001$ & 0.71 & $0.64-0.78$ & $<0.001$ & 0.72 & $0.61-0.85$ \\
\hline $\begin{array}{l}\text { Healthcare service use to overcome COVID-19 related } \\
\text { stress in the last } 6 \text { months }\end{array}$ & 3546 & 42.9 & 4718 & 57.1 & & & & & & \\
\hline No & 3049 & 42.4 & 4134 & 57.6 & Ref & & & Ref & & \\
\hline Yes & 497 & 45.9 & 584 & 54 & 0.030 & 0.87 & $0.76-0.99$ & 0.375 & 0.91 & $0.75-1.12$ \\
\hline
\end{tabular}

Adjusted for: age, gender, smoking, alcohol intake, living status, place of birth, country, education, employment status, employment stress, healthcare worker, financial impact, contact with COVID-19 case, experience due to COVID-19 and self-identification as a patient

living in the area where there was a rapid spread of infection [32].

Participants from the Middle East and war-torn countries reported less fear compared to the participants from South-East Asian countries and South Asia. The exact reasons for this could not be elicited from our study, however the reasons can be explained by two factors, firstly, high standard care and public health in Saudi Arabia, Kuwait and Oman, and success of early interventions, such as early lockdown reducing the transmission of COVID-19. It can be further emphasized that participants from war-torn countries already have experienced high levels of fear for prolonged periods which might cause an idiosyncratic response to the pandemic [33]. Further study on war-torn counties could provide more insights. Higher levels of fear of COVID-19 among participants from South-East Asian countries could be explained by their previous traumatic experience from SARS and H1N1 pandemics, which disproportionately affected South-East Asian countries [32].

In our study, we found that more than half of the participants $(57 \%)$ showed medium to high resilience towards the pandemic. Interestingly, participants from Australia found to struggle most, despite reports of very low levels of community transmission compared to the other 16 countries included in this study. This could be explained by the fact that Australian participants were predominantly from Victoria, the only state in Australia which was affected by the second wave of COVID-19 during the study period, which caused statewide strict lockdown, social isolation, job loss [16]. Nonetheless, despite potential lack of capacity and resources to manage pandemics, participants from war-torn countries like Palestine and Syria were found to have higher coping compared to the participants from Australia. It was beyond the scope of our study to examine the reasons for such findings. Research from Syria reported strategies to contain COVID-19, such as effective use of social media tools, community engagement, bottom-up approach from the local government, and coordinated support by the international donor communities [34].

\section{Limitations}

We had some limitations in our study. The use of online surveys potentially introduced selection bias, as participants were limited to those who could access the internet only; therefore, the generalizability of the findings needs to be interpreted with caution. Drawing predictive conclusions based on the differences is difficult and is a limitation of a cross sectional study design. Nevertheless, under the circumstances of movement restriction and social distancing, an online survey was the most robust available option during the pandemic to fulfill our research objectives. From the perspective of multi-country study (17 countries), the multicultural background, the difference of policies and compliance of public health actions that varied across participating countries, might also impact on the examined variables (psychological distress, fear, and ways of coping). We, therefore, adjusted the variable 'country' during the multivariate analyses to control potential confounding effects. Furthermore, the collaboration from researchers across 17 countries and the achievement of the target sample size during the crisis period of COVID-19 showed significant power to test our hypotheses and provided key information to plan interventions as needed.

\section{Conclusions}

Our study examined the extent and identified factors associated with psychological distress, fear of COVID19 and coping amongst diverse community members across 17 countries. Females and people with existing mental health issues were the most vulnerable group of populations for adverse psychological impact of COVID-19. There is an urgent need to prioritise 
Table 5 Country-wise analyses for high psychological distress, fear of COVID-19 and coping among the study participants

\begin{tabular}{|c|c|c|c|c|c|c|c|c|c|c|}
\hline \multirow[t]{3}{*}{ Characteristics } & \multicolumn{4}{|c|}{ K-10 Score } & \multicolumn{3}{|c|}{ Unadjusted analyses } & \multicolumn{3}{|c|}{ Adjusted analyses } \\
\hline & \multicolumn{2}{|c|}{ Low (score 10-15) } & \multicolumn{2}{|c|}{$\begin{array}{l}\text { Moderate to Very High } \\
\text { (score 16-50) }\end{array}$} & \multirow[b]{2}{*}{$\mathrm{p}$} & \multirow[b]{2}{*}{ ORs } & \multirow[b]{2}{*}{$95 \% \mathrm{Cls}$} & \multirow[b]{2}{*}{$\mathrm{p}$} & \multirow[b]{2}{*}{ AORs } & \multirow[b]{2}{*}{ 95\% Cls } \\
\hline & $\mathbf{n}$ & $\%$ & $\mathbf{n}$ & $\%$ & & & & & & \\
\hline Country of residence & \multicolumn{2}{|l|}{2634} & \multicolumn{2}{|l|}{5846} & & & & & & \\
\hline Thailand & 269 & 54.1 & 229 & 45.9 & \multicolumn{3}{|l|}{ Ref } & \multicolumn{3}{|l|}{ Ref } \\
\hline Hong Kong & 256 & 46.1 & 299 & 53.9 & 0.011 & 1.37 & $1.08-1.75$ & $<0.001$ & 1.93 & $1.37-2.73$ \\
\hline Indonesia & 223 & 41.2 & 318 & 58.8 & $<0.001$ & 1.68 & $1.31-2.14$ & 0.071 & 1.44 & $0.97-2.15$ \\
\hline Oman & 180 & 41.2 & 257 & 58.8 & $<0.001$ & 1.68 & $1.30-2.17$ & $<0.001$ & 2.20 & $1.50-3.25$ \\
\hline Nepal & 119 & 38.3 & 192 & 61.7 & $<0.001$ & 1.90 & $1.42-2.52$ & 0.253 & 1.28 & $0.84-1.95$ \\
\hline Malaysia & 273 & 37.9 & 447 & 62.1 & $<0.001$ & 1.92 & $1.53-2.42$ & \multicolumn{3}{|c|}{ Not included in multivariate model } \\
\hline Australia & 203 & 37.5 & 339 & 62.5 & $<0.001$ & 1.96 & $1.53-2.51$ & \multicolumn{3}{|c|}{ Not included in multivariate model } \\
\hline Libya & 38 & 33.3 & 76 & 66.7 & $<0.001$ & 2.35 & $1.53-3.60$ & $<0.001$ & 3.54 & $1.91-6.56$ \\
\hline Kuwait & 132 & 31.6 & 285 & 68.4 & $<0.001$ & 2.54 & $1.93-3.33$ & $<0.001$ & 3.06 & $2.05-4.58$ \\
\hline Bangladesh & 284 & 30.1 & 644 & 69.4 & $<0.001$ & 2.67 & $2.12-3.31$ & \multicolumn{3}{|c|}{ Not included in multivariate model } \\
\hline Pakistan & 121 & 28.9 & 297 & 71.1 & $<0.001$ & 2.88 & $2.19-3.80$ & 0.105 & 1.40 & $0.93-2.11$ \\
\hline Saudi Arabia & 225 & 28 & 578 & 71.9 & $<0.001$ & 3.02 & $2.38-3.81$ & $<0.001$ & 2.82 & $1.99-4.01$ \\
\hline UAE & 89 & 21.3 & 328 & 78.6 & $<0.001$ & 4.32 & $3.23-5.80$ & $<0.001$ & 3.68 & $2.31-5.86$ \\
\hline Jordan & 80 & 14.9 & 458 & 85.1 & $<0.001$ & 6.72 & $5.01-9.04$ & $<0.001$ & 6.83 & $4.05-11.5$ \\
\hline Syria & 53 & 13 & 355 & 87.0 & $<0.001$ & 7.87 & $5.61-11.0$ & $<0.001$ & 6.05 & $3.59-10.2$ \\
\hline Palestine & 50 & 12 & 367 & 88.0 & $<0.001$ & 8.62 & $6.11-12.2$ & $<0.001$ & 4.80 & $2.87-8.02$ \\
\hline Egypt & 39 & 9.4 & 377 & 90.6 & $<0.001$ & 11.4 & $7.81-16.5$ & $<0.001$ & 9.43 & $5.33-16.7$ \\
\hline \multirow[t]{3}{*}{ Characteristics } & \multicolumn{4}{|c|}{ FCV-19S Score } & \multicolumn{3}{|c|}{ Unadjusted analyses } & \multicolumn{3}{|c|}{ Adjusted analyses } \\
\hline & Low ( & e 7-21) & High & & & & & & & \\
\hline & $\mathbf{n}$ & $\%$ & $\mathbf{n}$ & $\%$ & $p$ & ORs & $95 \% \mathrm{Cls}$ & $\mathrm{p}$ & AORs & $95 \% \mathrm{Cls}$ \\
\hline Country of residence & 6420 & & 2066 & & & & & & & \\
\hline Libya & 104 & 91.2 & 10 & 8.8 & Ref & & & Ref & & \\
\hline Saudi Arabia & 714 & 88.9 & 89 & 11.1 & 0.458 & 1.30 & $0.65-2.57$ & 0.669 & 0.85 & $0.40-1.82$ \\
\hline Thailand & 427 & 85.7 & 71 & 14.3 & 0.123 & 1.73 & $0.86-3.46$ & 0.937 & 1.03 & $0.47-2.28$ \\
\hline Kuwait & 347 & 83.2 & 70 & 16.8 & 0.037 & 2.1 & $1.04-4.22$ & 0.395 & 1.40 & $0.64-3.07$ \\
\hline Oman & 351 & 80.3 & 86 & 19.7 & 0.008 & 2.55 & $1.28-5.08$ & 0.044 & 2.23 & $1.02-4.88$ \\
\hline Jordan & 429 & 79.7 & 109 & 20.3 & 0.005 & 2.64 & $1.34-5.23$ & 0.477 & 0.74 & $0.33-1.70$ \\
\hline Nepal & 248 & 79.7 & 63 & 20.3 & 0.007 & 2.64 & $1.31-5.35$ & 0.057 & 2.16 & $0.98-4.80$ \\
\hline Syria & 324 & 79.6 & 83 & 20.4 & 0.006 & 2.67 & $1.33-5.32$ & 0.455 & 1.35 & $0.62-2.93$ \\
\hline Palestine & 330 & 79.1 & 87 & 20.8 & 0.004 & 2.74 & $1.37-5.47$ & 0.844 & 1.09 & $0.49-2.42$ \\
\hline UAE & 320 & 76.7 & 97 & 23.3 & 0.001 & 3.15 & $1.59-6.27$ & 0.561 & 1.27 & $0.58-2.81$ \\
\hline Indonesia & 405 & 74.8 & 136 & 25.1 & $<0.001$ & 3.50 & $1.77-6.88$ & 0.006 & 2.86 & $1.35-6.08$ \\
\hline Malaysia & 525 & 72.9 & 195 & 27.1 & $<0.001$ & 3.87 & $1.98-7.54$ & Not inclu & $\mathrm{d}$ in $\mathrm{mu}$ & ariate model \\
\hline Egypt & 288 & 69.2 & 128 & 30.8 & $<0.001$ & 4.62 & $2.34-9.14$ & 0.055 & 2.13 & $0.98-4.62$ \\
\hline Hong Kong & 382 & 68.8 & 173 & 31.2 & $<0.001$ & 4.71 & $2.40-9.24$ & 0.003 & 3.21 & $1.47-7.01$ \\
\hline Australia & 374 & 68.1 & 175 & 31.8 & $<0.001$ & 4.87 & $2.49-9.54$ & Not inclu & $d$ in $m c$ & ariate model \\
\hline Pakistan & 281 & 67.2 & 137 & 32.8 & $<0.001$ & 5.07 & $2.57-10.0$ & 0.002 & 3.41 & $1.58-7.33$ \\
\hline Bangladesh & 571 & 61.5 & 357 & 38.4 & $<0.001$ & 6.50 & $3.35-12.6$ & Not inclu & $d$ in $m c$ & ariate model \\
\hline
\end{tabular}


Table 5 Country-wise analyses for high psychological distress, fear of COVID-19 and coping among the study participants (Continued)

\begin{tabular}{|c|c|c|c|c|c|c|c|c|c|c|}
\hline \multirow[t]{3}{*}{ Characteristics } & \multicolumn{4}{|c|}{ BRCS Score } & \multicolumn{3}{|c|}{ Unadjusted analyses } & \multicolumn{3}{|c|}{ Adjusted analyses } \\
\hline & \multicolumn{2}{|c|}{ Low (score 4-13) } & \multicolumn{2}{|c|}{ Medium to High (score 14-20) } & \multirow[b]{2}{*}{$\mathrm{p}$} & \multirow[b]{2}{*}{ ORs } & \multirow[b]{2}{*}{$95 \% \mathrm{Cls}$} & \multirow[b]{2}{*}{$\mathrm{p}$} & \multirow[b]{2}{*}{ AORs } & \multirow[b]{2}{*}{$95 \% \mathrm{Cls}$} \\
\hline & $\mathbf{n}$ & $\%$ & $\mathrm{n}$ & $\%$ & & & & & & \\
\hline Country of residence & 3665 & & 4815 & & & & & & & \\
\hline Australia & 534 & 97.3 & 15 & 2.7 & Ref & & & \multicolumn{3}{|l|}{ Ref } \\
\hline Libya & 70 & 61.9 & 43 & 38.1 & $<0.001$ & 21.86 & $11.6-41.4$ & \multicolumn{3}{|c|}{ Not included in multivariate model } \\
\hline Pakistan & 221 & 52.8 & 197 & 47.1 & $<0.001$ & 31.73 & $18.3-54.9$ & 0.210 & 1.40 & $0.83-2.36$ \\
\hline Jordan & 252 & 46.8 & 286 & 53.2 & $<0.001$ & 40.40 & $23.5-69.4$ & 0.014 & 1.99 & $1.15-3.43$ \\
\hline Egypt & 191 & 45.9 & 225 & 54.1 & $<0.001$ & 41.93 & $24.2-72.6$ & 0.003 & 2.28 & $1.33-3.88$ \\
\hline Saudi Arabia & 354 & 44.1 & 448 & 55.8 & $<0.001$ & 45.05 & $26.5-76.7$ & 0.016 & 1.84 & $1.12-3.02$ \\
\hline Kuwait & 183 & 43.8 & 234 & 56.1 & $<0.001$ & 45.52 & 26.3-78.8 & 0.009 & 2.01 & $1.20-3.40$ \\
\hline Bangladesh & 398 & 42.8 & 530 & 57.1 & $<0.001$ & 47.41 & $27.9-80.5$ & \multicolumn{3}{|c|}{ Not included in multivariate model } \\
\hline Hong Kong & 230 & 41.4 & 325 & 58.5 & $<0.001$ & 50.30 & 29.3-86.3 & 0.002 & 2.29 & 1.34-3.91 \\
\hline UAE & 151 & 36.5 & 262 & 63.4 & $<0.001$ & 61.77 & $35.6-107$ & $<0.001$ & 2.64 & $1.53-4.55$ \\
\hline Palestine & 152 & 36.5 & 264 & 63.4 & $<0.001$ & 61.83 & $35.7-107$ & $<0.001$ & 2.90 & $1.68-4.99$ \\
\hline Thailand & 175 & 35.1 & 323 & 64.9 & $<0.001$ & 65.71 & $38.1-113$ & 0.004 & 2.18 & $1.29-3.70$ \\
\hline Malaysia & 251 & 34.8 & 469 & 65.1 & $<0.001$ & 66.52 & $38.9-114$ & \multicolumn{3}{|c|}{ Not included in multivariate model } \\
\hline Oman & 137 & 31.4 & 300 & 68.7 & $<0.001$ & 77.96 & $44.9-135$ & $<0.001$ & 3.80 & $2.21-6.54$ \\
\hline Nepal & 97 & 31.2 & 214 & 68.8 & $<0.001$ & 78.54 & $44.6-138$ & $<0.001$ & 3.45 & 1.99-5.98 \\
\hline Indonesia & 156 & 28.8 & 385 & 71.2 & $<0.001$ & 87.86 & $50.9-152$ & $<0.001$ & 4.16 & $2.51-6.92$ \\
\hline Syria & 113 & 27.7 & 295 & 72.3 & $<0.001$ & 92.93 & $53.2-162$ & $<0.001$ & 4.94 & $2.89-8.46$ \\
\hline
\end{tabular}

Adjusted for: age, gender, smoking, alcohol intake, living status, place of birth, country, education, employment status, employment stress, healthcare worker, financial impact, contact with COVID-19 case, experience due to COVID-19 and self-identification as a patient

these vulnerable population; adequate medical and social support along with specific health promotion policies should be considered within the strategic response to the ongoing pandemic and future crises. Future studies should focus on developing strategies to enhance resilience and examining effectiveness of such interventions. Besides global strategies to address psychological impact, policy makers in each country should revisit existing support structures and enhance them during this critical period. Innovative approaches are needed to enhance effective coping and social support to alleviate impact and prevent emotional crisis for vulnerable people in the longer term.

\section{Supplementary Information}

The online version contains supplementary material available at https://doi. org/10.1186/s12992-021-00768-3.

Additional file 1: Table S1. Levels of psychological distress among the study participants (based on K-10 scoring). Table S2. Levels of fear of COVID-19 among the study participants (based on the FCV-19S scoring). Table S3. Coping during COVID-19 pandemic among the study participants. countries. We would like to convey our gratitude to all the study participants, who donated their valuable time within the crisis period of coronavirus pandemic and kindly participated in this global study.

Authors' contributions

MAR was the lead investigator, who conceptualised the study and had the responsibility to coordinate with the study investigators for data collection in 17 countries. MAR, SMSI, FS, SMA, BB, MS and WMC had substantial contribution to the conception or design of the study. Data collection was coordinated by the respective country lead: MAR in Australia, PT in Thailand, SG in Egypt, SYC in Hong Kong, AHAM and TSAM in Oman, AH and MAK in Syria, MH in Kuwait, ADS in Indonesia, ASBM in Malaysia, AA in Libya, DHE and RD in United Arab Emirates, FY in Pakistan, MAK in Jordan, NAL in Palestine, NO in Nepal, SA in Saudi Arabia, SR and TB in Bangladesh. MAR, FS, SMA and SJK cleaned, analysed and interpreted data. MAR, PT, FS, SMA, BB, MS, BJ, LL, MCW and SJK wrote the manuscript. SG, SYC, WTC, CS-L, NE-K, IM, AHAM, TSAM, RJA, AH, MAK, MH, AME provided critical feedback on narrative structure or methods or results. MAR, SMSI, FS and WMC finalised the manuscript and revised it critically for important intellectual content. All authors had full access to all the data in the study, accepted responsibility for its validity and had final responsibility for the decision to submit for publication.

Funding

We did not receive funding for this investigation.

Availability of data and materials

All data generated or analysed during this study are included in this published article.
We would like to acknowledge the support from all the collaborators and individuals who supported us in collecting data from the participating 


\section{Declarations}

\section{Ethics approval and consent to participate}

Ethics approval was obtained from the Human Research Ethics Committee from each participating country: Australia (Federation University Australia, Ref: B20-036), Bangladesh (Enam Medical College, Ref: EMC/ERC/2020/08-2), Egypt (Ain Shams University, Ref: FMASU R 121/2020), Hong Kong (The Chinese University of Hong Kong, Ref: SBRE-20-172), Indonesia (Universitas Indonesia, Ref: KET-1425/UN2.F1/ETIK/PPN.00.02/2020), Jordan (The Hashemite University), Kuwait (Kuwait University, Ref: VDR/EC/3693), Libya (Al-Brega General Hospital), Malaysia (Universitas Sains Malaysia, Ref: USM/JEPeM/ COVID19-40), Nepal (Kathmandu Medical College Public Ltd., Ref: 2611202004), Oman (Ministry of Health, Ref: MoH/CSR/20/24012), Pakistan (Lahore Garrison University), Saudi Arabia (Ministry of Health, Ref: 20-605E), Syria (University of Aleppo), Thailand (Chiang Mai University, Ref: AF 04-021), United Arab Emirates (Abu Dhabi University, Ref: CoHS-20-20-00024). Each study participant read the consent form along with plain language summary and ticked their consent in the online form prior to accessing the study questionnaire.

\section{Consent for publication}

Data were collected anonymously, therefore, no identifying information were collected from the study participants.

\section{Competing interests}

The authors confirm that there are no known conflicts of interest associated with this publication.

\section{Author details \\ ${ }^{1}$ School of Health, Federation University Australia, Berwick, Victoria, Australia. ${ }^{2}$ Australia Institute for Primary Care and Ageing (AIPCA), La Trobe University, Melbourne, Victoria, Australia. ${ }^{3}$ Department of Noncommunicable Diseases, Bangladesh University of Health Sciences (BUHS), Dhaka, Bangladesh. ${ }^{4}$ Deakin University, Burwood, Victoria, Australia. ${ }^{5}$ Faculty of Nursing, Chiang Mai University, Chiang Mai, Thailand. ${ }^{6}$ Telstra Health, Melbourne, Victoria, Australia. ${ }^{7}$ Monash University, Clayton, Victoria, Australia. ${ }^{8}$ The University of Melbourne, Melbourne, Victoria, Australia. ${ }^{9}$ Neurovascular Research Lab, Radiology Department, Mayo Clinic, Rochester, MN, USA. ${ }^{10}$ The Nethersole School of Nursing, The Chinese University of Hong Kong, Shatin, New Territories, Hong Kong. ${ }^{11}$ Psychiatric University Clinic UIm, UIm, Germany. ${ }^{12}$ Faculty of Medicine, Ain Shams University, Cairo, Egypt. ${ }^{13}$ Department of Public Health, College of Public Health and Health Informatics, Qassim University, Al Bukairiyah, Kingdom of Saudi Arabia. ${ }^{14}$ Ministry of Health, Muscat, Sultanate of Oman. ${ }^{15}$ Oman College of Health Sciences-South Sharquiya, Sur, Sultanate of Oman. ${ }^{16}$ Department of Emergency Medical Service, Jazan University, Jazan, Kingdom of Saudi Arabia. ${ }^{17}$ Faculty of Medicine, University of Aleppo, Aleppo, Syria. ${ }^{18}$ Faculty of Medicine, Kuwait University, Kuwait City, Kuwait. ${ }^{19}$ Faculty of Medicine for Girls, Al-azhar University, Cairo, Egypt. ${ }^{20}$ Department of Pulmonology and Respiratory Medicine, Universitas Indonesia, Jakarta, Indonesia. ${ }^{21}$ Advanced Medical and Dental Institute, Universiti Sains Malaysia, Penang, Malaysia. ${ }^{22}$ King Fahad Medical City, Riyadh, Kingdom of Saudi Arabia. ${ }^{23}$ Brega General Hospital, Brega, Libya. ${ }^{24}$ Enam Medical College \& Hospital, Dhaka, Bangladesh. ${ }^{25} \mathrm{Abu}$ Dhabi University, Abu Dhabi, United Arab Emirates. ${ }^{26}$ Lahore Garrison University, Lahore, Pakistan. ${ }^{27}$ The Hashemite University, Zarqa, Jordan. ${ }^{28}$ Department of Psychiatry and Psychotherapy, University of UIm, Ulm, Germany. ${ }^{29}$ Faculty of Pharmacy, Beni-Suef University, Minia, Egypt. ${ }^{30} \mathrm{Al}$ Azhar University-Gaza, Gaza strip, Palestine. ${ }^{31}$ Kathmandu Medical College, Kathmandu, Nepal. ${ }^{32}$ Department of Neurology, RWTH Aachen University, Aachen, Germany. ${ }^{33}$ Rangsit University, Pathum Thani, Thailand. ${ }^{34}$ Ministry of Health, Riyadh, Kingdom of Saudi Arabia. ${ }^{35}$ King Saud University Medical City, King Saud University, Riyadh, Kingdom of Saudi Arabia. ${ }^{36}$ National Institute of Cancer Research and Hospital, Dhaka, Bangladesh. ${ }^{37}$ Psychiatric Medical Staff Group, Persahabatan General Hospital, Jakarta, Indonesia.}

\section{Received: 28 June 2021 Accepted: 20 September 2021} Published online: 01 October 2021

\section{References}

1. WHO Coronavirus (COVID-19) Dashboard [https://covid19.who.int/]
2. Van Rheenen TE, Meyer D, Neill E, Phillipou A, Tan EJ, Toh WL, et al. Mental health status of individuals with a mood-disorder during the COVID-19 pandemic in Australia: Initial results from the COLLATE project. J Affect Disord. 2020;275:69-77.

3. Nochaiwong S, Ruengorn C, Thavorn K, Hutton B, Awiphan R, Phosuya C, et al. Global prevalence of mental health issues among the general population during the coronavirus disease-2019 pandemic: a systematic review and meta-analysis. Sci Rep. 2021;11(1):10173.

4. Stanton R, To QG, Khalesi S, Williams SL, Alley SJ, Thwaite TL, et al. Vandelanotte C: Depression, Anxiety and Stress during COVID-19: Associations with Changes in Physical Activity, Sleep, Tobacco and Alcohol Use in Australian Adults. Int J Environ Res Public Health. 2020; 17(11):4065.

5. Brooks SK, Webster RK, Smith LE, Woodland L, Wessely S, Greenberg N, et al. The psychological impact of quarantine and how to reduce it: rapid review of the evidence. Lancet. 2020;395(10227):912-20.

6. Wang C, Tee M, Roy AE, Fardin MA, Srichokchatchawan W, Habib HA, et al. The impact of COVID-19 pandemic on physical and mental health of Asians: A study of seven middle-income countries in Asia. PLoS One. 2021;16(2): e0246824

7. van Eersel JHW, Taris TW, Boelen PA. Complicated grief following job loss: Risk factors for its development and maintenance. Scand J Psychol. 2020; 61(5):698-706.

8. Gloster AT, Lamnisos D, Lubenko J, Presti G, Squatrito V, Constantinou M, et al. Impact of COVID-19 pandemic on mental health: An international study. PLoS One. 2020;15(12):e0244809.

9. Rahman MA, Hoque N, Alif SM, Salehin M, Islam SMS, Banik B, et al. Factors associated with psychological distress, fear and coping strategies during the COVID-19 pandemic in Australia. Global Health. 2020;16(1):95.

10. Lai J, Ma S, Wang Y, Cai Z, Hu J, Wei N, et al. Factors associated with mental health outcomes among health care workers exposed to coronavirus disease 2019. JAMA Netw Open. 2020;3(3):e203976.

11. Sze S, Pan D, Nevill CR, Gray $\sqcup$, Martin CA, Nazareth J, et al. Ethnicity and clinical outcomes in COVID-19: A systematic review and meta-analysis. EClinicalMedicine. 2020;29:100630.

12. Pfefferbaum B, North CS. Mental Health and the Covid-19 Pandemic. N Engl J Med. 2020;383(6):510-2.

13. Furukawa TA, Kessler RC, Slade T, Andrews G. The performance of the K6 and K10 screening scales for psychological distress in the Australian National Survey of Mental Health and Well-Being. Psychol Med. 2003;33(2): 357-62.

14. Ahorsu DK, Lin CY, Imani V, Saffari M, Griffiths MD, Pakpour AH. The Fear of COVID-19 Scale: Development and Initial Validation. Int J Ment Health Addict. 2020:1-9.

15. Sinclair VG, Wallston KA. The development and psychometric evaluation of the Brief Resilient Coping Scale. Assessment. 2004;11(1):94-101.

16. Rahman MA, Salehin M, Islam SMS, Alif SM, Sultana F, Sharif A, et al. Reliability of the tools used to examine psychological distress, fear of COVID-19 and coping amongst migrants and non-migrants in Australia. Int J Ment Health Nurs. 2021;30(3):747-58.

17. Chen L, Qu L. From Stressful Experiences to Depression in Chinese Migrant Children: The Roles of Stress Mindset and Coping. Front Psychol. 2021;12: 601732.

18. Gausman J, Langer A. Sex and Gender Disparities in the COVID-19 Pandemic. J Womens Health (Larchmt). 2020;29(4):465-6.

19. Wickens $C M, M c D o n a l d ~ A J$, Elton-Marshall T, Wells S, Nigatu YT, Jankowicz D, et al. Loneliness in the COVID-19 pandemic: Associations with age, gender and their interaction. J Psychiatr Res. 2021;136:103-8.

20. Stuart J, O'Donnell K, O'Donnell A, Scott R, Barber B. Online Social Connection as a Buffer of Health Anxiety and Isolation During COVID-19. Cyberpsychol Behav Soc Netw. 2021;24(8):521-5.

21. Sediri S, Zgueb Y, Ouanes S, Ouali U, Bourgou S, Jomli R, et al. Women's mental health: acute impact of COVID-19 pandemic on domestic violence. Arch Womens Ment Health. 2020;23(6):749-56.

22. Pappa S, Ntella V, Giannakas T, Giannakoulis VG, Papoutsi E, Katsaounou P. Prevalence of depression, anxiety, and insomnia among healthcare workers during the COVID-19 pandemic: A systematic review and meta-analysis. Brain Behav Immun. 2020;88:901-7.

23. He Z, Chen J, Pan K, Yue Y, Cheung T, Yuan Y, et al. The development of the 'COVID-19 Psychological Resilience Model' and its efficacy during the COVID-19 pandemic in China. Int J Biol Sci. 2020;16(15):2828-34. 
24. De Kock JH, Latham HA, Leslie SJ, Grindle M, Munoz SA, Ellis L, et al. A rapid review of the impact of COVID-19 on the mental health of healthcare workers: implications for supporting psychological well-being. BMC Public Health. 2021;21(1):104

25. Tsang HW, Fung KM, Corrigan PW. Psychosocial and socio-demographic correlates of medication compliance among people with schizophrenia. J Behav Ther Exp Psychiatry. 2009;40(1):3-14.

26. Clement J, Jacobi M, Greenwood BN. Patient access to chronic medications during the Covid-19 pandemic: Evidence from a comprehensive dataset of US insurance claims. PLoS One. 2021;16(4):e0249453.

27. Mazza C, Ricci E, Biondi S, Colasanti M, Ferracuti S, Napoli C, et al. A Nationwide Survey of Psychological Distress among Italian People during the COVID-19 Pandemic: Immediate Psychological Responses and Associated Factors. Int J Environ Res Public Health. 2020;17(9):3165.

28. Guan WJ, Ni ZY, Hu Y, Liang WH, Ou CQ, He JX, et al. Clinical Characteristics of Coronavirus Disease 2019 in China. N Engl J Med. 2020;382(18):1708-20.

29. Chodkiewicz J, Talarowska M, Miniszewska J, Nawrocka N, Bilinski P. Alcohol Consumption Reported during the COVID-19 Pandemic: The Initial Stage. Int J Environ Res Public Health. 2020;17(13):4677.

30. Achdut N, Refaeli T. Unemployment and Psychological Distress among Young People during the COVID-19 Pandemic: Psychological Resources and Risk Factors. Int J Environ Res Public Health. 2020:17(19):7163.

31. Lawrence $D$, Kisely $S$. Inequalities in healthcare provision for people with severe mental illness. J Psychopharmacol. 2010;24(4 Suppl):61-8.

32. Wong TW, Gao Y, Tam WWS. Anxiety among university students during the SARS epidemic in Hong Kong. Stress Health. 2007;23(1):31-5.

33. Al-Ashwal FY, Kubas M, Zawiah M, Bitar AN, Mukred Saeed R, Sulaiman SAS, et al. Healthcare workers' knowledge, preparedness, counselling practices, and perceived barriers to confront COVID-19: A cross-sectional study from a war-torn country, Yemen. PLoS One. 2020;15(12):e0243962.

34. Ekzayez A, Al-Khalil M, Jasiem M, Al Saleh R, Alzoubi Z, Meagher K, et al. COVID-19 response in northwest Syria: innovation and community engagement in a complex conflict. J Public Health (Oxf). 2020;42(3):504-9.

\section{Publisher's Note}

Springer Nature remains neutral with regard to jurisdictional claims in published maps and institutional affiliations.

Ready to submit your research? Choose BMC and benefit from:

- fast, convenient online submission

- thorough peer review by experienced researchers in your field

- rapid publication on acceptance

- support for research data, including large and complex data types

- gold Open Access which fosters wider collaboration and increased citations

- maximum visibility for your research: over $100 \mathrm{M}$ website views per year

At $\mathrm{BMC}$, research is always in progress.

Learn more biomedcentral.com/submissions 